\title{
Neuroendokrine Neoplasien der Lunge
}

\author{
Pulmonary Neuroendocrine Neoplasms
}

Autoren

Institute
Y. Sayeg ${ }^{1}$, M. Sayeg ${ }^{2}$, R. P. Baum ${ }^{3}$, H. R. Kulkarni ${ }^{3}$, N. Presselt ${ }^{4}$, I. Mäder ${ }^{1}$, A. Kunze ${ }^{5}$, J. Sänger ${ }^{5}$, D. Hörsch ${ }^{2}$, R. Bonnet ${ }^{1}$

Die Institutsangaben sind am Ende des Beitrags gelistet. eingereicht $\quad 3.2 .2014$ akzeptiert nach Revision 26.3.2014

Bibliografie Dol http://dx.doi.org/ 10.1055/s-0034-1365642 Pneumologie 2014; 68: 456-477 (c) Georg Thieme Verlag KG Stuttgart · New York ISSN 0934-8387

\section{Korrespondenzadresse} Yusef Sayeg

Zentralklinik Bad Berka GmbH Klinik für Pneumologie Robert-Koch-Allee 9 99437 Bad Berka pne@zentralklinik-bad-berka.de

\section{Zusammenfassung \\ $\nabla$}

Neuroendokrine Neoplasien der Lunge leiten sich von diffus im Körper verteilten enterochromaffinen Zellen her. Die Inzidenz der neuroendokrinen Neoplasien der Lunge ist in den letzten Jahrzehnten aufgrund der zur Verfügung stehenden Diagnostik deutlich angestiegen, sie machen etwa $1-2 \%$ aller Lungentumoren und ca. $20-30 \%$ aller neuroendokrinen Neoplasien aus. Die aktuelle WHO-Klassifikation ist aus dem Jahre 2004 und unterteilt typische Karzinoide (TC), atypische Karzinoide (AC), großzellige Lungenkarzinome (LCNEC) und kleinzellige Lungenkarzinome (SCLC). Die wichtigsten neuroendokrinen Biomarker sind Chromogranin A, CD56 und Synaptophysin. TC haben eine geringe Mitoserate von $<2$ Mitosen $/ 2 \mathrm{~mm}^{2}$ (10 HPFs), die Mitoserate der AC liegt bei 2-10 Mitosen $/ 2 \mathrm{~mm}^{2}$ (10 HPFs). Die Ki67-Färbungen sind zur Abgrenzung typischer bzw. atypischer Karzinoide von den hochmalignen LCNEC bzw. SCLC hilfreich. Klinisch fallen die Patienten zumeist mit Husten, Hämoptysen oder einer bronchialen Obstruktion auf. Das Auftreten eines Karzinoid- bzw. Cushing-Syndroms sowie eine tumorassoziierte paraneoplastische Akromegalie sind selten. Die chirurgische Resektion mit radikaler Lymphknotendissektion ist die Therapie der ersten Wahl zur Erreichung eines langfristigen Überlebens. Bei fehlender Operabilität bzw. Operationsfähigkeit des Patienten stellt die endoskopische Abtragung bei endobronchialem Tumorwachstum eine gute Alternative dar. Die Peptid-Rezeptor-Radionuklid-Therapie (PRRNT) ist eine vielversprechende Behandlungsmöglichkeit für Patienten mit metastasierten oder inoperablen neuroendokrinen Neoplasien der Lunge. Gezielte Therapien mit Angiogenese-Inhibitoren, Tyrosinkinase-Inhibitoren und mTOR-Inhibitoren werden in Studien auf ihre Effektivität und Wirksamkeit untersucht. Vielversprechende Daten lie-

\section{Abstract \\ $\nabla$}

The pulmonary neuroendocrine neoplasms originate from the enterochromaffin cells which are diffusely distributed in the body. The incidence of these tumors has increased significantly in recent decades due to the available diagnostics. They make up about $1-2 \%$ of all lung tumors and $20-30 \%$ of all neuroendocrine neoplasms. The current WHO classification from 2004 divides them into typical carcinoids (TC), atypical carcinoids (AC), large cell neuroendocrine carcinomas (LCNEC) and small cell carcinomas (SCLC). The major neuroendocrine biomarkers are chromogranin A, synaptophysin and CD56. TC have a low mitotic rate of $<2$ mitoses $/ 2 \mathrm{~mm}^{2}$ (10 HPF), whereas the mitotic rate of the AC is 2-10 mitoses $/ 2 \mathrm{~mm}^{2}$ (10 HPF). The Ki-67 staining is helpful to distinguish typical and atypical carcinoids from the highly malignant LCNEC and SCLC. Clinically, the patient presents usually with cough, hemoptysis or bronchial obstruction. The occurrence of a carcinoid or Cushing's syndrome and a tumor-associated acromegaly are rare. Surgical resection with radical lymph node dissection is the treatment of choice for achieving long-term survival. Endoscopic resection of the endobronchial tumor growth is a good alternative for inoperable endobronchially localized tumors. Peptide receptor radionuclide therapy (PRRT) is a promising treatment option for patients with metastatic or unresectable pulmonary neuroendocrine tumors. New targeted therapies using angiogenesis inhibitors, mTOR inhibitors, and tyrosine kinase inhibitors are being tested for their effectiveness in many previous studies. Typical carcinoid tumors metastasize less frequently than AC, the 5-year survival rate of patients with TC being over $90 \%$. Patients with AC have a 5 -year survival rate between $35 \%$ and $87 \%$. The highly malignant LCNEC and SCLC, on the other hand, 
gen für die Therapie mit Everolimus bereits vor. TC metastasieren seltener als AC, die 5-Jahres-Überlebensrate von Patienten mit TC liegt bei über $90 \%$. Patienten mit AC haben hingegen eine 5-Jahres-Überlebensrate zwischen $35 \%$ und $87 \%$ und die hoch-malignen LCNEC und SCLC eine 5-Jahres-Überlebensrate zwischen 15\% und $57 \%$ bzw. von unter $<5 \%$.

Die steigende Zahl der therapeutischen Möglichkeiten und diagnostische Verfahren erfordert ein multidisziplinäres Vorgehen und eine Entscheidungsfindung in multidisziplinären Tumorkonferenzen, um eine „maßgeschneiderte“ Therapie zu gewährleisten, weshalb Patienten mit einer neuroendokrinen Neoplasie der Lunge in spezialisierten Zentren behandelt werden sollten.

\section{Historischer Überblick}

\section{$\nabla$}

Neuroendokrine Neoplasien der Lunge bestehen aus hoch und mäßig differenzierten neuroendokrinen Tumoren der Lunge, die auch als typische und AC bezeichnet werden, sowie den schlecht differenzierten großzelligen neuroendokrinen (LCNEC) und kleinzelligen Lungenkarzinomen (SCLC), sie zeichnen sich durch eine neuroendokrine Differenzierung der Zellen aus. Sie wurden früher zu den bronchialen Adenomen gezählt. Wegen ihres Potentials zu metastasieren, werden sie jedoch heute als maligne Neubildungen betrachtet. Wie neuroendokrine Neoplasien an anderen Stellen des Körpers leiten sich auch die neuroendokrinen Neoplasien der Lunge von diffus im Körper verteilten neuroendokrinen Zellen ab, welche in der Embryogenese aus dem Neuralrohr in den Körper eingewandert sind.

Bereits R. Laennec beschrieb, wie nach seinem Tode 1831 publiziert wurde, eine intrabronchiale Masse. Wahrscheinlich war dies die erste schriftliche Erwähnung einer neuroendokrinen Neoplasie der Lunge. Lubarsch berichtete 1888 erstmals über Autopsieergebnisse zweier Patienten mit multiplen Tumoren des distalen Ileums. Oberndorfer fand 1907 bei sechs Patienten ebenfalls multiple Ileumtumore, die im Unterschied zu Karzinomen kein infiltratives Wachstum und keine Metastasierung aufwiesen. Daher prägte er den Begriff „Karzinoid“ (Karzinom-ähnlich). 1938 beschrieb Feyrter in der Mukosa des Tracheobronchialsystems „helle Zellen“, 1949 wurden diese von Froelich auch im Lungenparenchym gefunden. Ungefähr 20 Jahre später wurden von Pearse diese Zellen entsprechend ihrer histochemischen Eigenschaften dem APUD-Zellsystem (amin-precursor-uptake-and-decarboxylation) zugeordnet, da sie die Fähigkeit besitzen, Vorstufen biogener Amine aufzunehmen und zu decarboxylieren. Die daraus entstehenden Tumoren wurden als Apudome bezeichnet. Erspamer und Asero wiesen 1952 5-Hydroxytryptamin (Serotonin) in Mucosaextrakten des Gastrointestinaltraktes nach, und 1953 konnte Lambeck chromatografisch Serotonin bei einem Appendixkarzinoid darstellen [1].

Anhand histogenetischer Gesichtspunkte und je nach ihrer Lokalisation unterteilten Williams und Sandler 1963 die neuroendokrinen Neoplasien in:

- Vorderdarm,

- Mitteldarm

- und Enddarmkarzinoide [2].

Diese Klassifikation erwies sich jedoch aufgrund der biologischen und morphologischen Unterschiede der verschiedenen Tumorentitäten als zu ungenau. Arrigoni et al. hatten bereits 1972 die aggressiver wachsenden und früher metastasierenden neuroendokrinen Neoplasien als „atypisch“ von den „typischen“ abgegrenzt. 1991 schlugen Travis et al. ein 4-Klassen-Schema zur Klassifizierung der NEN vor. Dieses unterscheidet typische Karzi- have a 5-year survival rate between $15 \%$ and $57 \%$, and $<5 \%$ respectively.

The increasing number of therapeutic options and diagnostic procedures requires a multidisciplinary approach and decisionmaking in multidisciplinary tumor conferences to ensure a personalized treatment approach. Therefore patients with a neuroendocrine neoplasm of the lung should be treated in specialized centers.

noide (TC), atypische Karzinoide (AC), großzellige neuroendokrine Karzinome (LCNEC) und kleinzellige Lungenkarzinome (SCLC) [3]. Im Jahre 2004 wurden die WHO-Kriterien für die Diagnosestellung der neuroendokrinen Neoplasien der Lunge neu definiert. Neuroendokrine Neoplasien der Lunge sind nach denen des Gastrointestinaltraktes am zweithäufigsten. Andere typische Lokalisationen von neuroendokrinen Neoplasien sind der Thymus und die Ovarien.

Sie treten meist sporadisch, jedoch in bis zu 15\% im Rahmen eines MEN1-Syndroms auf.

\section{Das diffuse neuroendokrine System der Lunge $\nabla$}

Die aktuelle Bezeichnung PNEC (Pulmonale Neuroendokrine Zellen) schließt Zellen mit einem neuroendokrinen Phänotyp des respiratorischen Epithels ein. Neuroendokrine Zellen des respiratorischen Systems sind phylogenetisch weit verbreitet und entstammen dem Neuroektoderm. Beim Menschen wurden einzelne PNEC verstreut im gesamten respiratorischen Epithel nachgewiesen. Neuroendokrine Bodies (NEB) hingegen wurden bisher fast ausschließlich in den intrapulmonalen Atemwegen nachgewiesen. Borges et al. berichten von der Notwendigkeit des Critical Transcription Faktors (achaete-scute homologue-1) zur neuronalen Entwicklung bei murinen PNEC [4]. Auch wenn evidenzbasierte Daten belegen, dass PNEC neuroektodermalen Ursprungs sind, haben Ito et al. NEBs in fötalem respiratorischem Epithel ohne Zusammenhang mit neuralem Gewebe nachweisen können [5].

\section{Lokalisation und Morphologie}

Beim Menschen wurden einzelne PNEC verstreut in den oberen und unteren Atemwegen nachgewiesen. NEBs hingegen konnten fast ausschließlich in den unteren Atemwegen nachgewiesen werden. PNEC haben oft eine dreieckige Zellform, wobei sich der überwiegende Anteil des zytoplasmatischen Inhalts in der Nähe der Basalmembran befindet. Der apikale Anteil ist schmal und kann bis in das Lumen der Atemwege reichen. NEBs sind häufig in der Nähe von Bifurkationen der Atemwege und der bronchoalveolären Grenzzonen zu finden und besetzen somit strategische Positionen zur Erfassung der Sauerstoffkonzentration. Sie bestehen aus Clustern von PNEC und bilden ein intraepitheliales „Organ“, das mit seinem basalen Anteil und mit vorstehenden Mikrovilli in das Atemwegslumen ragt und seinen apikalen Anteil innerviert [6]. 


\section{Funktionen des diffusen neuroendokrinen Systems der Lunge \\ $\nabla$}

\section{Sauerstoffsensoren}

Es wird angenommen, dass NEBs spezialisierte Sauerstoffsensoren des Atemwegsystems sind. Sie stehen in engem Kontakt mit Nervenfasern. Eine Hypoxämie ist ein starker Stimulus der NEB und führt zur Exozytose der Dense Core Vesikel, welche Peptide sowie Serotonin enthalten [7]. Der genaue Mechanismus des Sauerstoffsensors ist noch nicht komplett aufgeklärt. Ein membrangebundener Enzymkomplex, wie die NADPH-Oxidase, könnte ein potenzieller Rezeptor sein [8].

\section{Regulation der Lungenentwicklung}

Die hohe Anzahl von PNEC in der späten fötalen und neonatalen Phase ist wahrscheinlich mit der Lungenentwicklung assoziiert. Während der pulmonalen Organogenese sind PNEC die ersten Zellen, die heranreifen [9]. Es wird postuliert, dass die von den PNEC ausgeschütteten Peptide einen für die Lungenentwicklung wichtigen parakrinen Stimulationseffekt auf die umliegenden Epithelzellen haben. Bombesin Like Peptide (BLP) und Calcitonin Gene Related Peptide (CGRP) scheinen einen mitogenen sowie reifenden Effekt zu besitzen [10]. Sie fungieren als Wachstumsfaktoren für verschiedene Lungenzelltypen und stimulieren die Atemwegsverzweigung und die Differenzierung der Zellen [11]. Zudem ist bekannt, dass mechanischer Zug für das Lungenwachstum und die Differenzierung in der fötalen Periode wichtig ist. Pan et al. nehmen an, dass PNEC sowie NEB Eigenschaften eines Mechanorezeptors und Chemorezeptors besitzen. Eine mechanische Belastung führt über mechanosensitive Kanäle zur Freisetzung von Serotonin aus den fötalen PNEC [12].

\section{Regulation des pulmonalen Blutflusses}

Pulmonale neuroendokrine Zellen produzieren Substanzen mit vasoaktiven Eigenschaften. Serotonin, welches von den PNEC bei Hypoxämie ausgeschüttet wird, ist ein starker Vasokonstriktor [13]. Darüber hinaus wird CGRP, ein pulmonaler Vasodilatator, bei Normoxämie ausgeschüttet. Während einer Hypoxämie ist die Ausschüttung von CGRP reduziert und führt daher möglicherweise ebenfalls zu einer Vasokonstriktion [14].

\section{Regulation des bronchialen Tonus}

Neuroendokrine Zellen der Lunge sind wahrscheinlich auch mit beteiligt bei der Regulation des Tonus der Bronchien. In Zellkulturen wurde gesehen, dass das Neuropeptid CGRP glatte Muskelzellen der Atemwege zusammenzieht und es somit zur Kontraktion derselben kommt. Bei Hypoxämie bewirkt die verminderte Ausschüttung der neuroendokrinen Zellen eine physiologische Bronchodilatation [15].

\section{Epidemiologie}

Pulmonale neuroendokrine Neoplasien machen etwa 1-2\% aller Lungentumoren im Erwachsenenalter und ca. 20 - 30\% aller neuroendokrinen Neoplasien aus [16-20]. ( Tab.1) Das Verhältnis von TC zu AC liegt bei etwa 4:1. Die Inzidenz liegt zwischen 0,2 bis 2 Fälle auf 100000 Einwohner. Frauen sind häufiger betroffen als Männer [16,17,21,22]. Daten aus der Zentralklinik Bad Berka von 61 Patienten mit einer histologisch gesicherten neuroendokrinen Neoplasie der Lunge zeigen eine Geschlechtsverteilung von ungefähr 2:1 zu Gunsten des weiblichen Geschlechts bei den TC und
Tab. 1 Statistische Daten zum Lungenkarzinoid.

$1-2 \%$ aller Lungentumoren
$25 \%$ aller Karzinoide
$80-90 \%$ typische Karzinoide
$10-20 \%$ atypische Karzinoide
$70-80 \%$ proximal, 20 - $30 \%$ peripher
$61 \%$ liegen rechtsseitig, v. a. im Mittellappen

Tab. 2 Geschlechtsverteilung aus einer retrospektiven Analyse von Patienten, die im Beobachtungszeitraum 2002 bis 2010 in der Klinik für Thoraxchirurgie der Zentralklinik Bad Berka an der Lunge wegen eines Lungenkarzinoides operiert wurden.

\begin{tabular}{|llll|}
\hline & Geschlecht & $\mathbf{n}$ & $\%$ \\
\hline Gesamtkollektiv $(\mathrm{n}=61)$ & männlich & 25 & 41 \\
\hline Typisches Karzinoid $(\mathrm{n}=32)$ & weiblich & 36 & 59 \\
\hline & männlich & 11 & 34,4 \\
\hline Atypisches Karzinoid $(\mathrm{n}=27)$ & weiblich & 21 & 65,6 \\
\hline LCNEC $(\mathrm{n}=2)$ & männlich & 13 & 48,1 \\
\hline & weiblich & 14 & 51,9 \\
\hline & männlich & 1 & 50 \\
\hline
\end{tabular}

eine weitgehend homogene Geschlechtsverteilung bei den AC sowie den LCNEC ( Tab.2). In der Literatur der letzten 20 Jahre gibt es nur wenige Arbeiten, die sich mit NEN der Lunge im Kindesalter befassen, sodass es sehr schwierig ist, Angaben über deren Inzidenz zu machen. Dennoch zählen neuroendokrine Neoplasien der Lunge zu den häufigsten malignen Lungenerkrankungen bei Kindern und präsentieren sich typischerweise erst im späten Jugendalter. Die ansteigende Inzidenz in den letzten Jahrzehnten ist am ehesten auf die bessere bildgebende Diagnostik zurückzuführen, welche viele asymptomatische Tumoren detektiert. Das Durchschnittsalter bei Diagnosestellung von TC liegt bei 45 Jahren. AC werden im Durchschnitt erst 10 Jahre später manifest $[23,24]$. Ihre Inzidenz ist in den USA innerhalb der letzten 30 Jahre mit $6 \%$ pro Jahr rapide angestiegen [25]. TC repräsentieren $80-90 \%$ der NEN der Lunge und treten gehäuft in der 5. und 6. Lebensdekade auf. In der SEER-Datenbank (Surveillance Epidemiology and End Results) repräsentieren LCNEC 0,3\% aller NEN der Lunge. Takei H. et al. geben Inzidenzen von bis zu $3 \%$ an [26]. LCNEC kommen gehäuft in der 7. Lebensdekade vor. Dabei sind Männer viermal häufiger betroffen als Frauen. SCLCs werden durchschnittlich zwischen dem 60. und 70. Lebensjahr diagnostiziert und machen in den USA 9,8\% und laut den ESMO-Guidelines (M. Früh et al. Ann Oncol 2013) von 2013 in Europa ca. 13\% aller malignen Lungentumoren aus $[23,25,27]$.

\section{Risikofaktoren}

Ein Zusammenhang zwischen Lungen-NEN und Nikotinkonsum ist nicht sicher bewiesen. In einer Studie war die Raucheranamnese bei 44 von 63 Patienten mit durchschnittlich 28 pack years positiv [28]. In einer weiteren Analyse von Erasmus et al. waren von den Patienten 33\% mit TC und 64\% mit AC aktive Raucher oder hatten eine positive Raucheranamnese [29]. Andere Autoren berichten in retrospektiven Analysen von einer positiven Raucheranamnese im Patientenkollektiv von bis zu 30\% (TC) und $80 \%$ (AC) [30]. Auch in aktuellen Daten aus der Zentralklinik 
Tab.3 Organmanifestationen und Symptomatik beim MEN1- und MEN2-Syndrom.

\begin{tabular}{|c|c|c|c|}
\hline Syndrom & Gen & Neuroendokrine Tumoren & Andere Tumoren \\
\hline $\begin{array}{l}\text { Multiple endokrine Neoplasie } \\
\text { Typ } 1 \text { (MEN1) }\end{array}$ & $\begin{array}{l}\text { MEN1, } \\
\text { auf Chromosom } 11\end{array}$ & $\begin{array}{l}\text { D Primärer Hyperparathyroidismus (>90\%) } \\
\text { - Enteropankreatik }(30-80 \%) \\
\text { - Gastrinom } \\
\text { - Insulinom } \\
\text { - VIPOM } \\
\text { - Glukagonom } \\
\text { - Andere bzw. unbekannt } \\
\text { - Hypophyse (30-65\%) } \\
\text { - Prolactinom } \\
\text { - STH-om (Akromegalie) } \\
\text { - GTHom } \\
\text { - ACTHom } \\
\text { - Inaktiv } \\
\text { D Nebenniere (19\%) }\end{array}$ & $\begin{array}{l}\text { NEN der Lungen } \\
\text { Thymuskarzinom } \\
\text { Nebennierenadenom } \\
\text { Angiofibrome } \\
\text { Dermale Tumoren }\end{array}$ \\
\hline $\begin{array}{l}\text { Multiple endokrine Neoplasie } \\
\text { Typ } 2 \text { (MEN2A) }\end{array}$ & RET & $\begin{array}{l}\text { Schilddrüsenkarzinom (>90\%) } \\
\text { Pheochromozytom ( } 40-50 \%) \\
\text { Paraschilddrüsenhyperplasie (10-20\%) } \\
\text { Primär kutane Amyloidose }\end{array}$ & Schleimhautneurome \\
\hline $\begin{array}{l}\text { Multiple endokrine Neoplasie } \\
\text { Typ } 2 \text { (MEN2B) }\end{array}$ & & $\begin{array}{l}\text { Medulläres Schilddrüsenkarzinom } \\
\text { Pheochromozytom }\end{array}$ & Schleimhautneurome \\
\hline
\end{tabular}

Modifiziert nach Simon et. al. Dtsch Arztebl 2000; 97 (11): A-698/B-569/C-535 und Thakker RV, Newey PJ, Walls GV et al. Clinical practice guidelines for multiple endocrine neoplasia type 1 (MEN1). J Clin Endocrinol Metab 2012; 97: 2990.

Bad Berka hatten 54\% der Patienten mit einem AC und 56\% der Patienten mit einem TC eine positive Raucheranamnese.

\section{Genetik und Pathogenese}

Patienten mit dem autosomal dominanten Syndrom der multiplen endokrinen Neoplasie Typ I ( $\bullet$ Tab.3) weisen eine hohe Inzidenz von neuroendokrinen Neoplasien auf ( $\mathbf{A b b}$. 1). Eine nicht MEN1-assoziierte familiäre Häufung neuroendokriner Neoplasien der Lunge wird ebenfalls beschrieben [31]. Die Inzidenz der MEN1-assoziierten neuroendokrinen Neoplasien außerhalb des Duodenums und Pankreas liegt zwischen 5 bis 9\% [32].

Basierend auf den Beobachtungen von Nirupa et al., sind neuroendokrine Neoplasien der Lunge in mindestens 5\% und möglicherweise in bis zu 31\% mit einem MEN1-Syndrom des Erwachsenen mit einer geschlechtsspezifischen Prävalenz zugunsten der weiblichen Bevölkerung assoziiert [33]. Anders als neuroendokrine Neoplasien des Thymus, die einen aggressiven klinischen Verlauf mit schlechter Prognose haben, verhalten sich NEN der Lunge bei Patienten mit MEN1 eher indolent, obwohl die Potenz zur Metastasierung und die Rezidivneigung postoperativ gegeben ist. Es wird vermutet, dass ein chromosomaler Verlust in der Region 11q13 (MEN1-Gen) signifikant an der Pathogenese von Lungen NEN beteiligt ist [34].

Eine mutationsbedingte Inaktivierung des MEN1-Gens ist in ca. $74 \%$ der TC, $70 \%$ der AC, $52 \%$ der LCNEC und in ca. $42 \%$ des SCLC nachweisbar [34-36].

Die hohe Inzidenz der MEN1-Mutationen bei pulmonalen NEN zeigt, dass ein genetisches Screening für MEN1 bei Personen mit TC und AC durchgeführt werden sollte. Aktuell wird ein genetisches MEN1-Screening jedoch erst bei Vorhandensein von mehr als zwei MEN1-assoziierten Tumoren empfohlen. Ab einem Alter von 20 Jahren sollten Patienten mit einem MEN1-Syndrom in dreijährigen Abständen eine Computertomografie des Thorax erhalten, um rechtzeitig eine pulmonale NEN zu erkennen [37]. Loss of heterozygosity $(\mathrm{LOH})$ in der Region $3 \mathrm{p}$ ist die häufigste genetische Alteration und scheint häufig bei den LCNEC sowie SCLC aufzutreten (40\% TC, 73\% AC, 83\% LCLC und 85\% SCLC). Abnorme Expression oder LOH und Punktmutationen des p53-Locus wurden in $4 \%$ der TC, $29 \%$ der AC, $80 \%$ der LCNEC, und $75 \%$ der SCLC festgestellt. Die verschiedenen Muster von p53-Mutationen zwischen TC/AC und LCNEC/SCLC unterstützen die Hypothese, dass diese zwei Gruppen genetisch verschieden sind. Eine Studie über die Häufigkeit der p53-Protein-Expression zeigte $0 \%$ für TC, $20 \%$ für AC, $42 \%$ für SCLC und $86 \%$ in LCNEC, was darauf hindeutet, dass p53 verwendet werden könnte, um zwischen Subtypen von NEN der Lunge zu unterscheiden. Die Expression vom p53-Protein korreliert mit einem höheren Apoptoseindex bei AC. Beim SCLC zeigt eine hohe Expression von p53 eine schlechte Prognose an [38].

\section{Pathologie und Klassifikation \\ $\nabla$}

Die NEN der Lunge sind klinisch sehr heterogen. TC sind hochdifferenziert, langsam wachsend und metastasieren selten in extrathorakale Strukturen. Das SCLC ist biologisch aggressiv und zeigt ein schnelles Wachstum mit früher Metastasierung. Das biologische Verhalten von AC liegt dazwischen. Ungeachtet ihres heterogenen klinischen Verhaltens teilen Lungentumoren mit neuroendokriner Differenzierung einige morphologische und biochemische Charakteristika, wie z.B. die Fähigkeit, Neuropeptide zu synthetisieren, und das Vorhandensein von submikroskopischen, zytoplasmatisch dichten (neuroendokrinen) Granula, die elektronenmikroskopisch nachgewiesen werden können.

\section{TNM-Klassifikation}

Die TNM-Klassifikation der NEN der Lunge ist identisch mit der TNM-Klassifikation anderer Lungentumoren. 


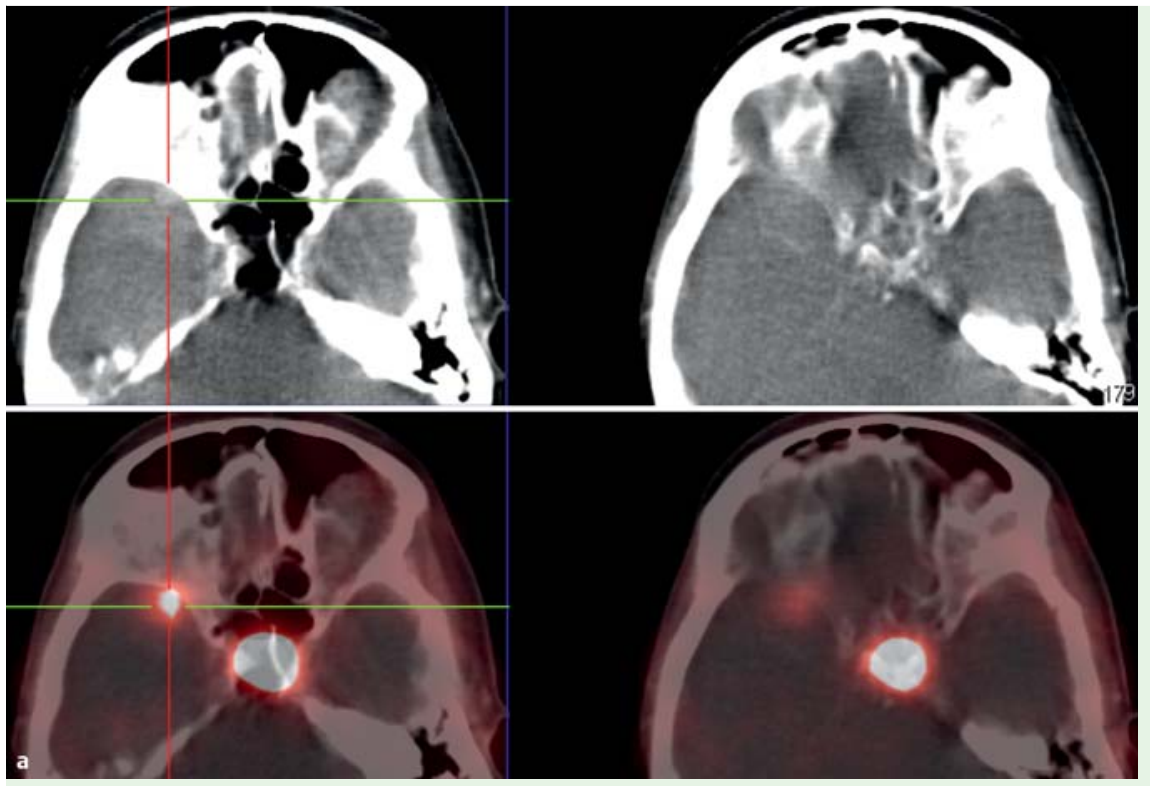

Abb. 1 Heterogenität der klinischen Präsentation eines MEN1-Syndroms bei einer 58-jährigen Patientin. Ga-68 DOTATOC Somatostatinrezeptor PET/CT: Hypophysenadenom/Prolaktinom (a) - gleichzeitig dargestellt ist ein rechts frontales Meningeom sowie atyp. Karzinoid der Lunge (b) und Nachweis eines kleinen Pankreastumors im PET/CT (c). Histologisch gesichert ist darüber hinaus ein Hyperparathyreoidismus.
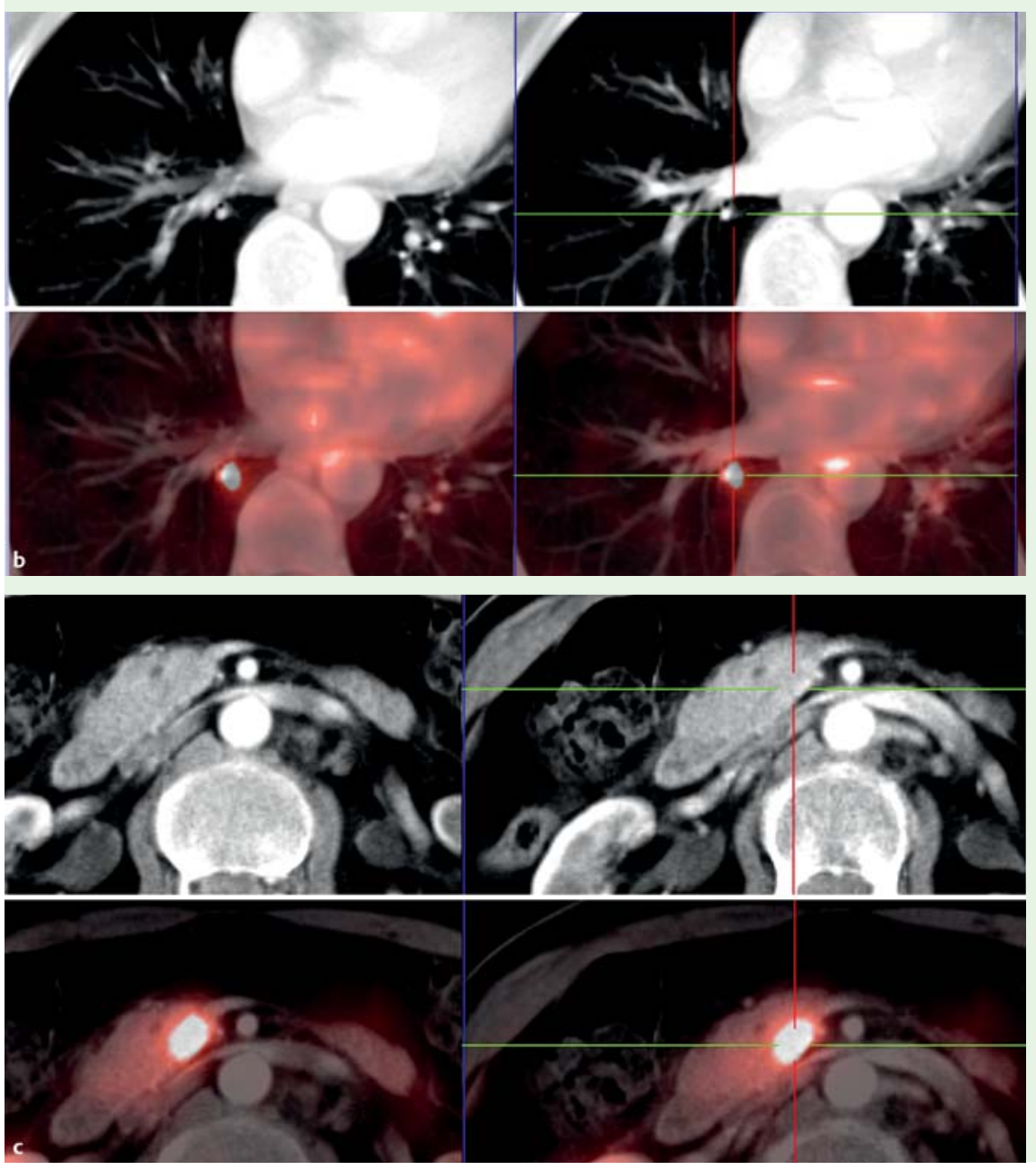
Tab. 4 2004 WHO-Kriterien für die Diagnose der neuroendokrinen Tumoren.

\begin{tabular}{|c|c|}
\hline Tumortyp & Kriterien \\
\hline $\begin{array}{l}\text { Diffuse idiopathische neuroendokrine } \\
\text { Zellhyperplasie (DIPNECH) }\end{array}$ & $\begin{array}{l}\text { Proliferation verstreuter einzelner Zellen, kleine Noduli oder lineare Proliferation der pulmonalen } \\
\text { neuroendokrinen Zellen, die auf die Bronchien bzw. auf das bronchiale epitheliale Gewebe begrenzt sind }\end{array}$ \\
\hline $\begin{array}{l}\text { Typische Karzinoidtumoren } \\
\text { (low-grade) }\end{array}$ & $\begin{array}{l}\text { Karzinoidmorphologie und }<2 \text { Mitosen } / 2 \mathrm{~mm}^{2}(10 \mathrm{HPF} \text { ), keine Nekrose und }>0,5 \mathrm{~cm} \\
\text { Azzopardi-Effekt: keiner }\end{array}$ \\
\hline $\begin{array}{l}\text { Atypische Karzinoidtumoren } \\
\text { (intermediate-grade) }\end{array}$ & $\begin{array}{l}\text { Karzinoidmorphologie mit } 2 \text { - } 10 \text { Mitosen/2 mm² (10 HPFs) oder Nekrose (oft punktuell angeordnet) } \\
\text { Azzopardi-Effekt: keiner }\end{array}$ \\
\hline \multirow[t]{5}{*}{$\begin{array}{l}\text { Großzellige neuroendokrine Karzinome } \\
\text { (high-grade malignancies) }\end{array}$} & $\begin{array}{l}\text { neuroendokrine Morphologie (organoide Strukturen mit trabekulären, rosettenförmigen oder } \\
\text { palisadenartigen Strukturen) }\end{array}$ \\
\hline & hohe Mitoserate $>10 / 2 \mathrm{~mm}^{2}$ (10 HPFs), im Median 70/2 mm²; Azzopardi-Effekt: selten \\
\hline & Nekrose (oft große Regionen) \\
\hline & $\begin{array}{l}\text { zytologische Eigenschaften von NSCLC: große Zellen, kleines Verhältnis von Zellkern zum Zytoplasma, } \\
\text { Einige Tumoren weisen feines nukleäres Chromatin und fehlende Nukleoli auf, zählen jedoch aufgrund } \\
\text { ihrer Zellgröße und ihres reichlichen Zytoplasmas zu den NSCLC. }\end{array}$ \\
\hline & $\begin{array}{l}\text { positive immunhistochemische Markierung für ein oder mehrere NE- Marker (andere als NSE) und/oder } \\
\text { neuroendokrine Granulae im Elektronenemissionsmikroskop }\end{array}$ \\
\hline \multirow{5}{*}{$\begin{array}{l}\text { Kleinzellige neuroendokrine Karzinome } \\
\text { (high-grade malignancies) }\end{array}$} & kleine Zellen (normalerweise kleiner als 3 Lymphozyten \\
\hline & geringes Zytoplasma \\
\hline & Nuklei: feines granuläres Chromatin, keine oder matte Nukleoli. Azzopardi-Effekt: gelegentlich \\
\hline & hohe Mitoserate: > 11 Mitosen/2 mm² (10 HPFs), im median 80/2 mm² (10HPFs); und \\
\hline & öfter Nekrosen, sehr häufig große Zonen \\
\hline
\end{tabular}

HPF: high-power field; NSCLC: non-small cell lung carcinoma; NE: Neuroendokrine

Azzopardi- Effekt: Basophilie-Färbung der Gefäßwände infolge von Ablagerung der DNS des nekrotischen Tumors

\section{WHO-Klassifikation}

Neuroendokrine Tumoren der Lunge waren in der Vergangenheit Gegenstand einer beträchtlichen Kontroverse. Hieraus resultierten multiple, teils unübersichtliche und verwirrende Klassifikationen. Die letzte, allgemein akzeptierte WHO-Klassifikation stammt aus dem Jahre 2004 [39]. In ihr werden neuroendokrine Tumoren der Lunge in ein klinisch-pathologisches Spektrum eingeteilt, welches von der diffusen idiopathischen neuroendokrinen Zellhyperplasie (DIPNECH) bis hin zum schlecht differenzierten kleinzelligen Lungenkarzinom und zu den großzelligen neuroendokrinen Karzinomen reicht ( $\bullet$ Tab.4). Neuroendokrine pulmonale Zellhyperplasien und Tumorlets (TC mit einem Durchmesser von kleiner als $5 \mathrm{~mm}$ ) stellen wahrscheinlich eine frühe Manifestationsform der neuroendokrinen Tumoren des Bronchialsystems dar $[38,40]$. Die WHO-Klassifikation definiert DIPNECH als eine Proliferation verstreuter einzelner Zellen, kleine Noduli oder lineare Proliferation der pulmonalen neuroendokrinen Zellen, die auf die Bronchien bzw. auf das bronchiale epitheliale Gewebe begrenzt sind [45]. Sobald sie die Basalmembran durchbrechen, bezeichnet man sie als Tumorlets $(<5 \mathrm{~mm})$ bzw. als Karzinoid-Tumoren $(>5 \mathrm{~mm}$ ). Initial wurden diese in klinischen Zusammenhang gebracht mit chronischen Lungenerkrankungen wie der obliterativen Bronchiolitis, Bronchiektasien und der idiopathischen Lungenfibrose. Tumorlets sind „benigne Hyperplasien“ von geringer klinischer Relevanz, jedoch weisen jüngste Studien auf die potenzielle Malignität dieser Strukturen hin $[41,42]$.

\section{Immunhistochemie}

\section{Immunohistochemie (TC und AC)}

Chromogranin A, CD56 und Synaptophysin sind die wichtigsten neuroendokrinen Marker. Eine geringe Mitoserate von $<2$ Mitosen $/ 2 \mathrm{~mm}^{2}$ (10 HPFs) und fehlende Nekrosen werden bei TC beobachtet, während die Mitoserate der AC bei 2-10 Mitosen/ $2 \mathrm{~mm}^{2}$ (10 HPFs) liegt. Ein weiteres typisches Merkmal AC ist das Vorhandensein von Nekrosen. In kleinen, gequetschten Biopsien ist die Ki-67-Färbung zur Abgrenzung typischer bzw. atypischer Karzinoide von high-grade LCNEC bzw. SCLC sehr hilfreich $[43,44](\bullet$ Abb.2).

\section{Immunhistochemie (LCNEC)}

Die histologischen Kriterien zur Diagnosestellung eines LCNEC unterscheiden sich von denen des TC bzw. AC. Immunhistochemisch sollte mindestens ein neuroendokriner Marker (Chromogranin A, CD56, Synaptophysin) außer NSE nachgewiesen werden. Die Mitoserate muss über 10 Mitosen $/ 2 \mathrm{~mm}^{2}$ (10 HPFs) liegen [3].

Der Thyroidale Transkriptionsfaktor 1 (TTF-1) ist bei LCNEC in bis zu 75\% positiv ( $\bullet$ Abb.3). TTF-1 wird, ähnlich wie bei den Adenokarzinomen der Lunge, in etwa $75 \%$ der Tumore nukleär exprimiert. Eine Abgrenzung zu den Adenokarzinomen gelingt durch den oben beschriebenen Nachweis von mindestens 2 neuroendokrinen Markern und die typische neuroendokrine Morphologie. Darüber hinaus lässt sich mit Zytokeratinen (z.B. AE1/3, MNF, Lu5) bei allen neuroendokrinen Neoplasien und somit auch beim LCNEC eine charakteristische punkt- oder kappenförmige paranukleäre Färbung erreichen, die man bei anderen Karzinomen nicht findet. Auch die bei den LCNEC ausgesprochen hohe Proliferationsrate (MIB1/Ki-67) wäre für ein Adenokarzinom ungewöhnlich. In diesem Kontext muss man auch die Adenokarzinome mit neuroendokriner Aktivität nennen. Diese exprimieren zwar neuroendokrine Marker, zeigen aber nicht das typische Wuchsmuster und die hohe Proliferationsrate der LCNEC. Im Gegensatz zu SCLC gelingt bei den LCNEC kein Nachweis der hochmolekularen Zytokeratine 1, 5, 10 und 14, dies hat in der Routinediagnostik jedoch wenig Relevanz $[45,46]$.

Die Diagnosestellung anhand einer Nadelbiopsie ist oft schwierig, da in der kleinen Gewebsprobe die charakteristische Morphologie häufig nicht zu erkennen ist und demzufolge kein entsprechendes Markerpanel zum Einsatz kommt. Daher gelingt eine eindeutige präoperative histologische Diagnosesicherung nur selten. 


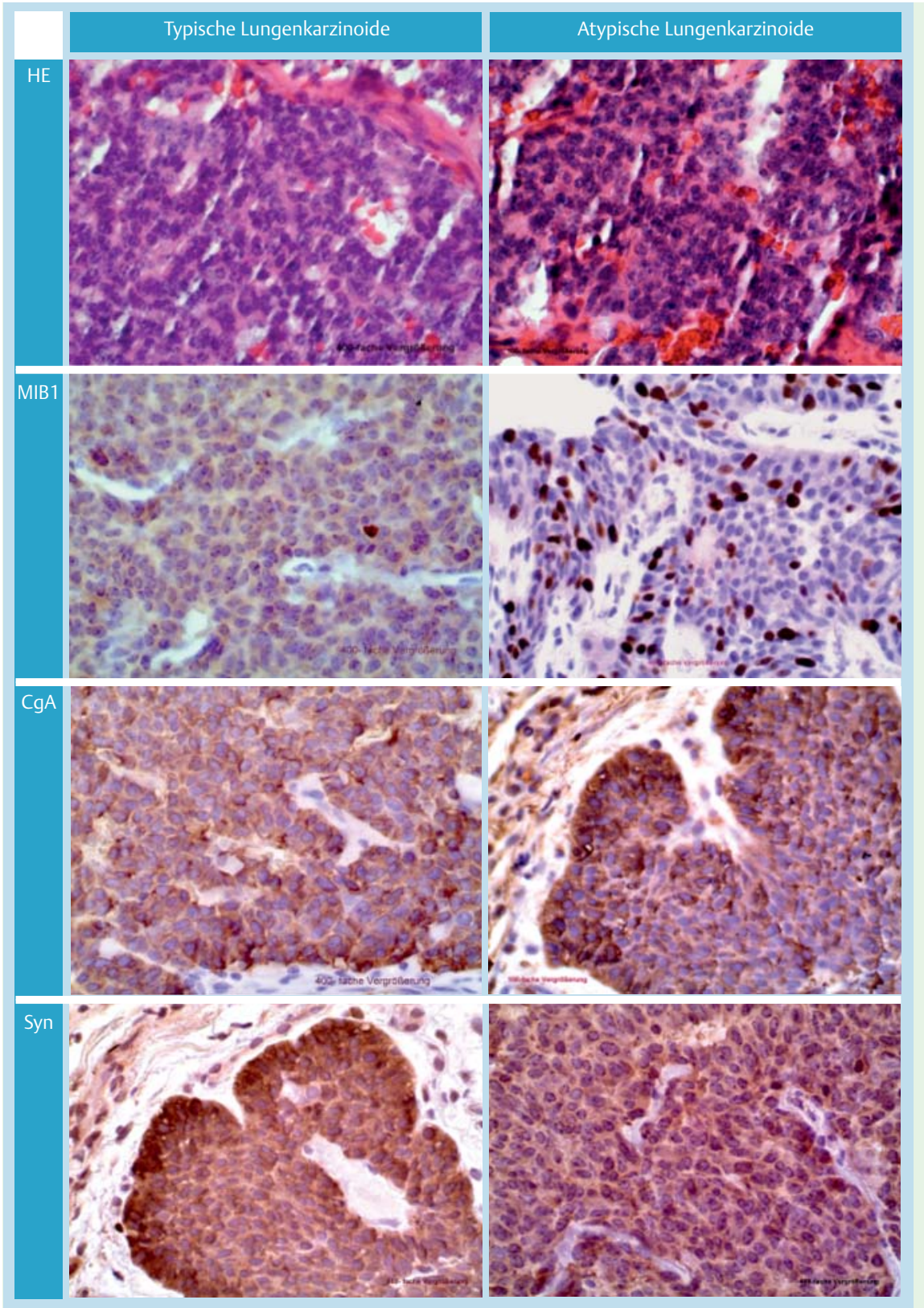

Abb.2 Histopathologie/Immunhistochemie beim typischen und atypischen Lungenkarzinoid (HE: Hämatoxylin eosin, MIB1: Antikörper gegen Ki-67, CgA: Chromogranin A, Syn: Synaptophysin).

Immunhistochemie (SCLC)

Trotz typischer Morphologie ist zur Diagnosesicherung des SCLC die immunhistochemische Färbung sehr hilfreich. Die empfohlenen Färbungen für die Diagnose eines SCLC beinhalten Panzytokeratin-Antikörper, wie z.B. AE1/AE3, welche eine typische paranukleäre punktförmige Markierung zeigen. Dies erlaubt eine Abgrenzung lymphozytärer Infiltrate. Darüber hinaus belegen CD56, Chromogranin A und Synaptophysin die neuroendokrine Differenzierung. Allerdings ist die Expression von Chromogranin A und Synaptophysin beim SCLC im Vergleich zu den anderen neuroendokrinen Neoplasien der Lunge typischerweise nur schwach ausgeprägt. CD56 gilt daher als sensitivster Marker für SCLC ( $\bullet$ Abb.3). Der Nachweis einer hohen proliferativen Aktivität mittels Ki-67 erlaubt die Diskriminierung von TC und AC. Wenn keine Immunreaktivität gegenüber panepithelialen Markern nachweisbar ist, müssen ggf. andere Tumoren, insbesondere Lymphome (CD45 und CD20), aber auch primitive neuroektodermale Tumore (CD99) und Melanome (S100) in Betracht gezogen werden. In 70 bis $80 \%$ der SCLC ist TTF-1 positiv [47]. Die Differenzialdiagnose eines SCLC von der eines nichtkleinzelligen Lungentumors ist in ca. 5\% der Fälle sehr schwierig $[48,49]$.

\section{Klinik}

$\nabla$

Die Mehrzahl der neuroendokrinen Neoplasien der Lunge (80\%) entsteht in den proximalen Atemwegen, wobei Beschwerden meistens durch die Stenosierung der Atemwege infolge der Tumormasse bedingt sind und die Patienten demzufolge unter Husten, Giemen, Luftnot oder wiederkehrenden Infektionen durch Retentionspneumonien im gleichen Lungensegment oder Lungenlappen leiden ( $\bullet$ Abb.4). Zudem können aufgrund der typischen Hypervaskularisation der Tumoren Blutungen mit Hämoptysen oder Hämatoptoe entstehen. Gelegentlich treten Brustschmerzen auf. Die Diagnose wird meist spät gestellt. Häufig werden Patienten längere Zeit symptomatisch oder bei rezidi- 


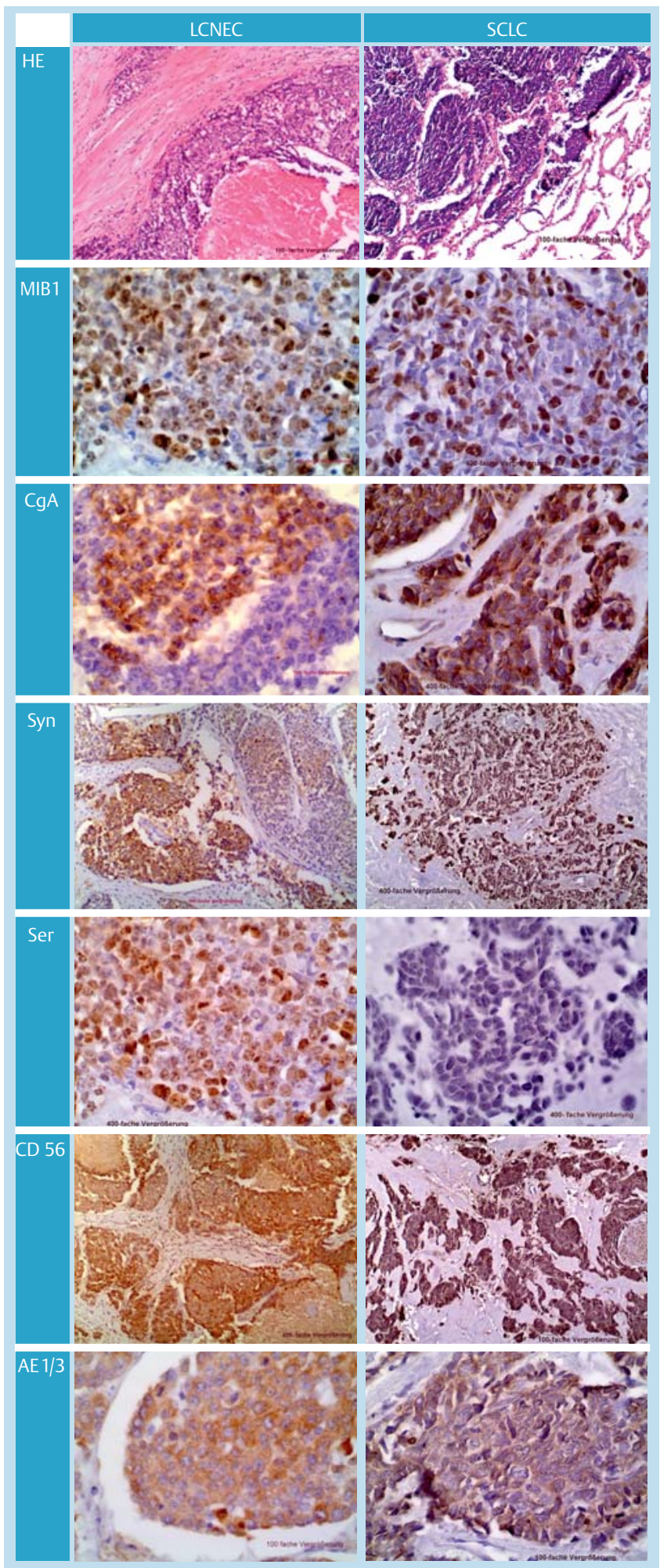

Abb. 3 Histopathologie/Immunhistochemie LCNEC und SCLC (HE: Hämatoxylin eosin, MIB1: Antikörper gegen Ki-67, CgA: Chromogranin A, Ser: Serotonin, Syn: Synaptophysin)

vierenden Infekten mit verschiedenen Antibiotika therapiert. Im Gegensatz hierzu sind Patienten mit neuroendokrinen Neoplasien der peripheren Lunge meist asymptomatisch. Diese Tumoren werden häufig als Zufallsbefund bei Röntgen-Thoraxaufnahmen gefunden. Weniger als $5 \%$ aller Tumore sind bei Diagnosestellung funktionell aktiv [45].

\section{Peptid-Produktion und paraneoplastische Syndrome}

Der Abbau von Serotonin erfolgt durch das Enzym Monoaminooxidase zu 5-Hydroxyindolessigsäure, die renal ausgeschieden wird ( $\bullet$ Abb.5). Der unausgeglichene Tryptophanmetabolismus der NEN führt über Hydroxylierung großer Mengen von Tryptophan zu 5-HTP, 5HT und 5-HIAA [50]. Wenn in den Karzinoidzellen ein Mangel an Aromatischer-L-Aminosäure-Decarboxylase (AADC) herrscht, kann 5-HTP nicht in Serotonin überführt werden, und der Tumor produziert statt Serotonin 5-HTP [51]. Normalerweise werden rund 99\% des Tryptophans zur Synthese von Nikotinsäure benutzt und nur $1 \%$ zu Serotonin metabolisiert. Im Tumorgewebe wandelt sich das Verhältnis zu Gunsten des Serotonins (40\% Nikotinsäure, $60 \%$ Serotonin) um, wobei der sinkende Nikotinsäurespiegel bei Patienten mit NEN der Lunge in seltenen Fällen zu Pellagra führt, aber üblicherweise kein Karzinoidsyndrom verursacht [52]. NEN der Lunge sezernieren nur wenige Amine. Daraus resultiert, dass der Hormonspiegel im Plasma bzw. im Urin oft niedrig ist und die Diagnosestellung erschwert. Nur ein geringer Anteil der Patienten bietet ein paraneoplastisches Syndrom. Karzinoidsyndrome kommen bei einer Tumorgröße von weniger als $5 \mathrm{~cm}$ selten vor und sind meist mit dem Vorhandensein von Lebermetastasen vergesellschaftet [53].

\section{Karzinoidkrise}

Im Gegensatz zu NEN anderen Ursprungs ist die Wahrscheinlichkeit des Auftretens einer Karzinoidkrise bei pulmonalen NEN eher gering. Biopsien oder Manipulationen an einem aktiv sezernierenden NEN der Lunge können in seltenen Fällen zu einer Karzinoidkrise durch massive systemische Ausschüttung von bioaktiven Mediatoren führen [54]. Koronare Spasmen und Herzstillstand stellen eine seltene Manifestation der Karzinoidkrise während der Manipulation eines pulmonalen NEN [55] dar, müssen aber in der Klinik Beachtung finden, da die Therapieansätze einer Karzinoidkrise von den allgemeinen Reanimationsleitlinien stark abweichen. Bedingt sind die koronaren Spasmen durch den akuten Anstieg des Serumserotonin- sowie Histaminspiegels. Anästhetika wie Thiopentan, d-Tubocurarine, Suxamethonium und Morphine sollten daher vermieden werden. Präoperativ sollte

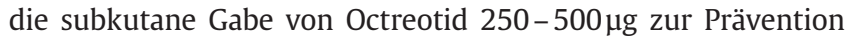
einer Karzinoidkrise erfolgen. Während einer therapierefraktären Hypotension oder eines Herzstillstandes sollte der Schwerpunkt auf eine adäquate Volumensubstitution gelegt werden. Auf den Einsatz von Katecholaminen sollte verzichtet werden, da diese die Hormonausschüttung weiter stimulieren und paradoxerweise die Hypotension verschlimmern [60]. Die intravenöse Gabe von 100-500 $\mu \mathrm{g}$ Somatostatin bewirkt eine rasche Beendigung einer Karzinoidkrise und ihrer hämodynamischen Komplikationen [56].

\section{Cushing-Syndrom}

Die Assoziation von ektoper ACTH-Produktion und einem NEN der Lunge wurde erstmals von Brown 1928 erkannt und von Liddle et al. 1962 beschrieben. In 1-2\% der Fälle entwickeln Patienten mit einem TC bzw. AC der Lunge ein Cushing-Syndrom. Der Beginn ist oft akut und mit einer Hypokaliämie vergesellschaftet. Die Diagnosestellung ist schwierig, da die Produktion von ACTH durch neuroendokrine Neoplasien der Lunge, im Gegensatz zu anderen Tumoren mit ektoper ACTH-Produktion, durch Dexamethason unterdrückt sein kann. Die Mehrzahl der ACTH-produzierenden neuroendokrinen Neoplasien der Lunge ist kleiner als zwei Zentimeter, was die Diagnose ebenfalls er- 


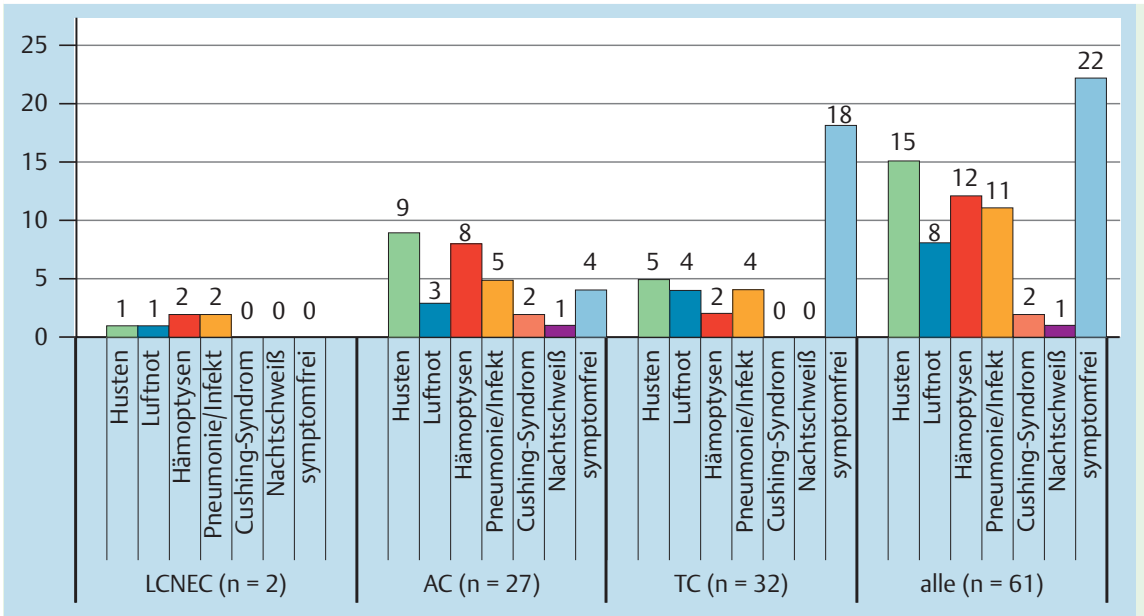

Abb.4 Symptome bei ärztlicher Erstvorstellung (Patientenkollektiv Zentralklinik Bad Berka).

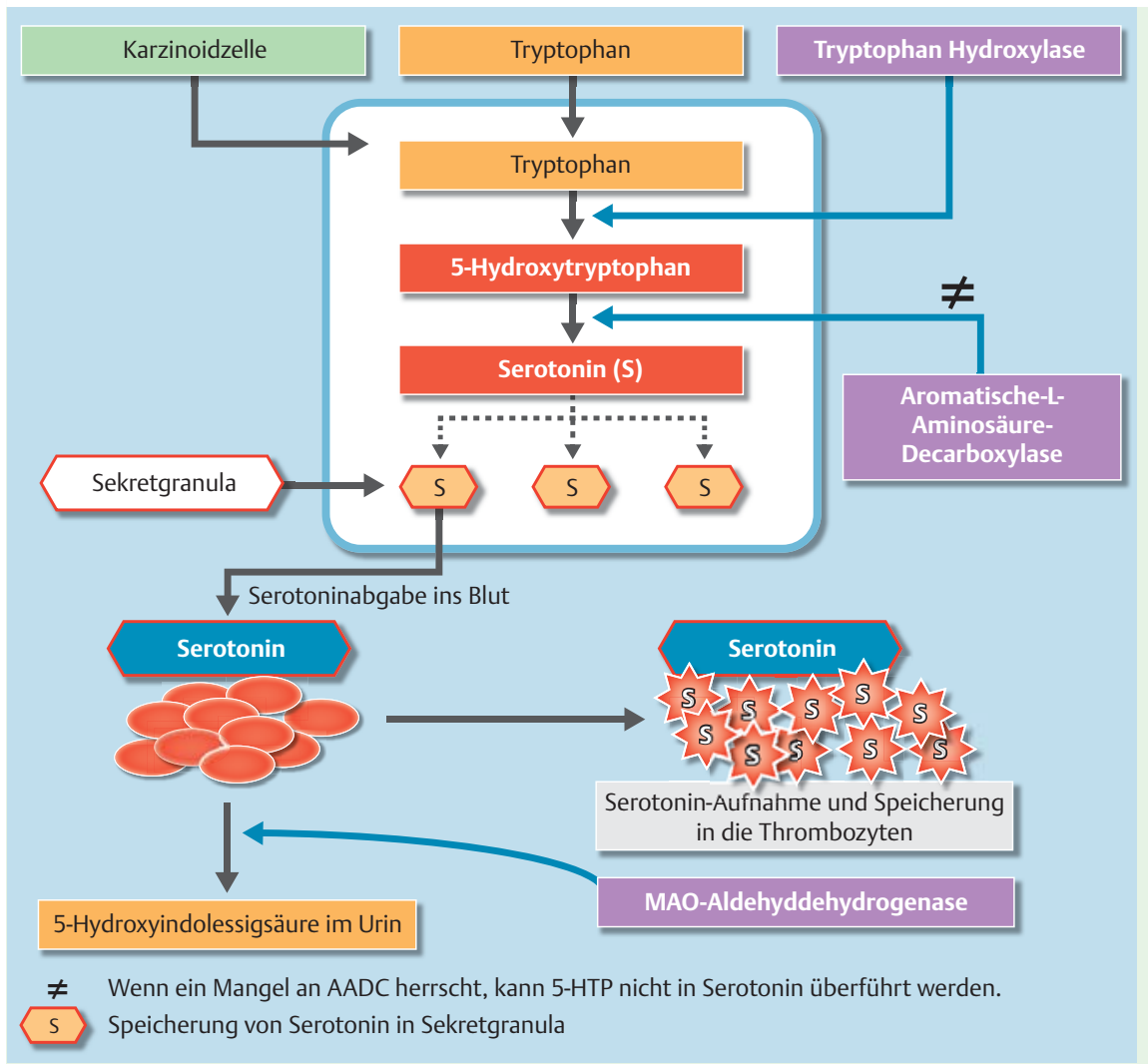

Abb.5 Tryptophanmetabolismus der Karzinoidzelle.

schwert [57]. Neuroendokrine Neoplasien der Lunge sind die häufigste Ursache (25\%), hingegen führen SCLC (11\%) und disseminierte neuroendokrine Tumore unklaren Ursprungs (7\%) seltener zur Ausbildung eines Cushing-Syndroms [58]. Ein langanhaltendes Cushing-Syndrom bedarf eines Rezidivausschlusses bzw. einer Metastasensuche [59,60]. Einige Studien belegen, dass ACTH-produzierende NEN aggressiver sind als hormonell inaktive $[61,62]$.

\section{Akromegalie}

Eine Akromegalie infolge ektoper Produktion von GHRH (Growth-hormone-releasing hormone) und Insulin-like-Growth Factor 1 (IGF-1) durch eine neuroendokrine Neoplasie der Lunge ist extrem selten (<1\%) [63], wobei sie die häufigste Ursache für eine ektope GHRH-Sekretion ist [64-67]. Eine operative Resektion der neuroendokrinen Neoplasie führt zu einem Abfall des
GH-Spiegels mit Regredienz der Akromegalieerscheinungen [68, 69]. Im Falle einer Irresektabilität können Somatostatinanaloga eingesetzt werden, die das ektope GH-Releasing-Hormon supprimieren [70]. Somatostatin (SMS)-Analoga kontrollieren nicht nur die endokrine Hypersekretion, sondern auch die Tumorproliferation [63].

\section{Hedinger-Syndrom}

Hohe Konzentrationen von Serotonin und anderer vasoaktiver Substanzen, die vom Tumor ausgeschüttet werden, gelangen bei Vorhandensein von Lebermetastasen über die V. cava inferior in das rechte Herz und lösen eine Fibrosierung an der Trikuspidalund Pulmonalklappe aus. (TIPS-Prozess=Trikuspidalklappeninsuffizienz und Pulmonalstenose) [71,72]. Eine Linksherzbeteiligung tritt in bis zu 10\% der Fälle auf, wenn eine neuroendokrine Neoplasie der Lunge Serotonin direkt in das linke Herz ausschüt- 


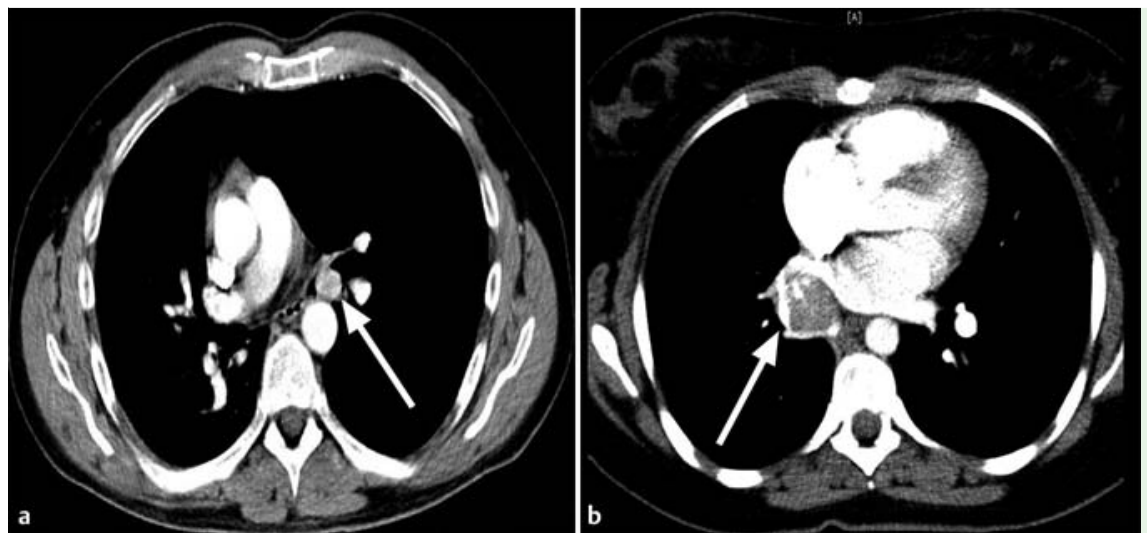

Abb.6a, b Zentral gelegenes, kugelartiges Karzinoid li. und re.
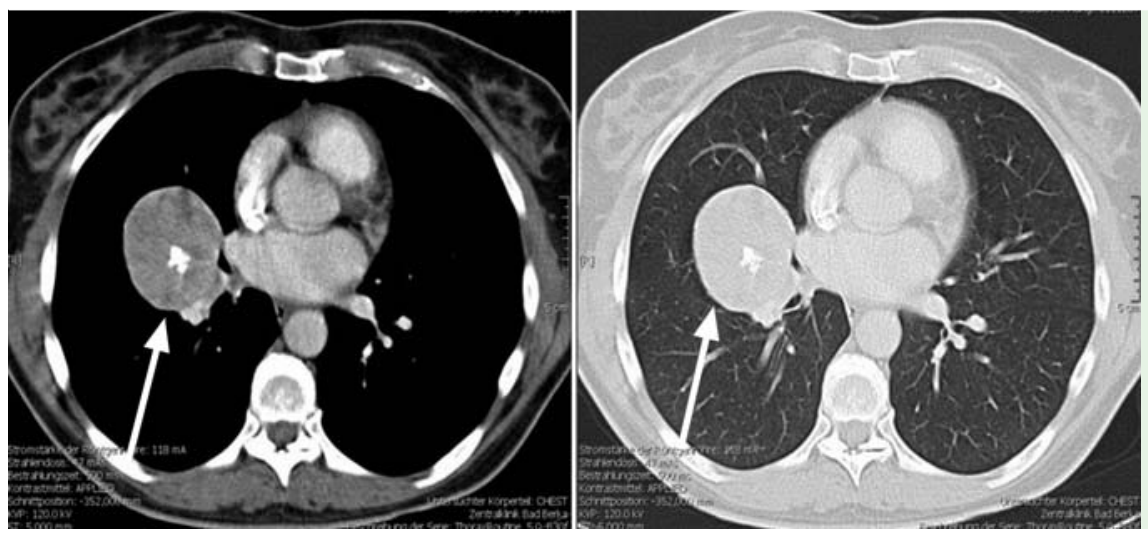

Abb.7 Zentral gelegenes Karzinoid rechts mit Verkalkung (Pfeil).

tet [73]. Fortgeschrittene Veränderungen der Trikuspidalklappe korrelieren mit einem schlechten Langzeitüberleben [74]. Ein Hedinger-Syndrom ist in ca. einem Drittel der Fälle unabhängig von der Metastasierung prognoselimitierend [75]. Fast 95\% der Patienten mit rechtsseitiger Herzklappenerkrankung entwickeln im Verlauf eine pulmonale Hypertonie [76].

\section{Diagnostik \\ $\nabla$}

Labor

Chromogranin A wurde aus chromaffinen Zellen der adrenalen Medulla isoliert. Bei Herzinsuffizienz wird es im Ventrikelmyokard produziert und von dort ins Blut freigesetzt [77]. Chromogranin A ist ein geeigneter Tumormarker zur Verlaufskontrolle, jedoch aufgrund der fehlenden Spezifität nicht zur Diagnosestellung geeignet. Die Höhe des Chromogranin-A-Serumspiegels korreliert in gewisser Weise mit der Tumorlast [78]. Ein erhöhter Chromogranin-A-Serumspiegel kann ebenfalls bei SCLC, Mamma- und Prostatakarzinomen nachweisbar sein [79]. Erhöhte Werte können darüber hinaus durch Begleiterkrankungen (Niereninsuffizienz, Herzinsuffizienz, Gastritis, Bluthochdruck, COPD, septischer Schock) bzw. Medikamenteneinnahme (Protonenpumpenhemmer, H2-Rezeptorantagonisten) auftreten [80]. Der Nachweis einer erhöhten 5-HIES-Konzentration im 24-h-Urin ist spezifisch und sensitiv bei funktionell aktiven NEN des Dünndarms, selten jedoch bei NEN der Lunge. Die Bestimmung von Serotonin im Blut spielt aufgrund hoher interindividueller tageszeitlicher Schwankungen und aufgrund serotoninreicher Nahrungsmittel in der klinischen Diagnostik eine eher untergeordnete Rolle [81]. Die Serotoninbestimmung aus den Thrombozyten ist sensitiver als die 5-HIES-Bestimmung aus dem Urin und wird nicht durch eine serotoninreiche Diät beeinflusst [82]. Freigesetztes Serotonin wird u.a. aktiv durch Thrombozyten aufgenommen und in Granula gespeichert ( $\mathbf{A b b}$.5). Die Spezifität dieser Bestimmung liegt zwar bei nahezu 100\%, aufgrund einer Sensitivität von nur 35\% hat sie sich daher aber noch nicht etabliert [83]. Auch die neuronenspezifische Enolase (NSE) kann bei neuroendokrinen Tumoren pathologisch erhöht sein, jedoch hat die Bestimmung im Serum aufgrund der relativ geringen Sensitivität und Spezifität des Markers keine Bedeutung erlangt [84].

\section{Röntgen-Thorax Übersichtsaufnahme}

75\% der Patienten mit einer NEN der Lunge haben eine auffällige Röntgen-Thorax Übersichtsaufnahme. Die meisten Raumforderungen sind rund bis oval, haben einen Durchmesser von ca. 2 $5 \mathrm{~cm}$ und sind meist hilär bzw. perihilär gelegen. Bis zu $40 \%$ befinden sich in der Lungenperipherie [85]. Eine Kavernenbildung ist sehr selten. Eine pleurale Mitbeteiligung ist unüblich, kann aber mit einer postobstruktiven Pneumonie vergesellschaftet sein.

\section{Computertomografie des Thorax}

Die meisten TC und AC stellen sich im CT als isodense Tumoren dar. Zwischen 5 und $20 \%$ der TC sind mit hilären oder mediastinalen Adenopathien assoziiert [86]. Lymphknotenmetastasen treten häufiger bei AC auf. Computertomografisch erscheinen die NEN der Lunge als eine sphärische, längliche oder ovale Gewebsformation ( $\bullet$ Abb.6a,b) mit gut definierten lobulierten Grenzen, die typischerweise in der Nähe der zentralen Bronchien lokalisiert sind, oft bifurkationsnah. Kalzifizierungen sind normalerweise in der Röntgen-Thorax Übersichtsaufnahme nicht sichtbar, aber in der CT in bis zu 30\% der Fälle nachweisbar [87]. Zentral gelegene NEN weisen häufig Kalzifikationen auf ( $\bullet$ Abb.7) 


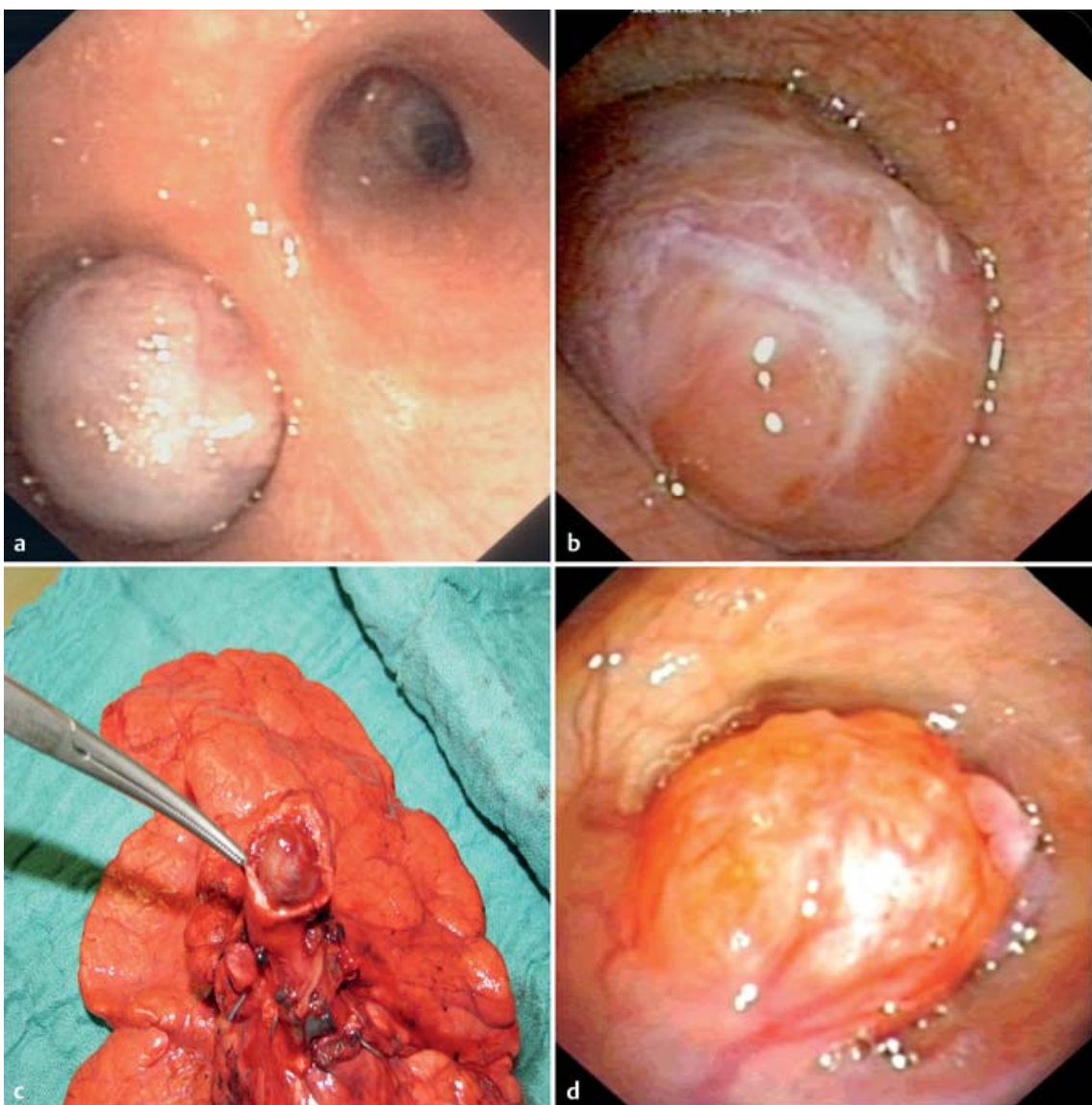

Abb.8 a Neuroendokrine Neoplasie im Zwischenbronchus, b Neuroendokrine Neoplasie im li. Hauptbronchus, c Operationspräparat/makroskopisches Bild (gleicher Patient wie im Bild b), d stark vaskularisierte neuroendokrine Neoplasie im proximalen Zwischenbronchus.

[88]. Intratumorale Kalzifikationen werden bei $9 \%$ der Patienten mit LCNEC gesehen [89]. AC sind im Vergleich zu TC mit einem Durchmesser von durchschnittlich 3,6 cm größer $(\mathrm{TC} 2,3 \mathrm{~cm})$ und vorwiegend peripher lokalisiert [90]. Es kann mittels HRCT der Lunge meist zwischen einem intra- und extraluminalen Tumorbefall unterschieden und in Folge dessen die weitere Therapie, wie z. B. eine bronchoskopische Abtragung in kurativer Intention bei funktionell nicht operablen Patienten geplant werden [91].

\section{Magnetresonanztomografie}

Die Durchführung einer MRT kann zur Differenzierung zwischen kleinen kontrastmittelaufnehmenden peripheren NEN und pulmonalen Gefäßen bzw. zur Abgrenzung vaskulärer Invasionen eines zentral gelegenen NEN hilfreich sein und wird in der Diagnostik im Kinder- und Jugendalter bevorzugt [92]. Zur Darstellung von Lebermetastasen ist das MRT ein sensitiveres Verfahren und sollte daher dem CT vorgezogen werden.

\section{Echokardiografie}

Regelmäßige Echokardiografiekontrollen sollten im Rahmen des Restagings zur rechtzeitigen Erfassung eines tumorassoziierten Hedinger-Syndroms bei Nachweis einer Serotoninproduktion der NEN erfolgen.

\section{Bronchoskopie und endobronchiale Endosonografie}

Ungefähr 75\% der TC und AC liegen zentral und sind einer Biopsie zugänglich. Bronchoskopisch sieht man eine typische rosa bis rot vaskularisierte Struktur mit intaktem bronchialem Epithel. Neuroendokrine Neoplasien liegen gewöhnlich dem Bronchus

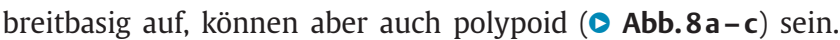
Ein zytologischer Bürstenabstrich ist sensitiver als die Zytologie des Sputums. Der diagnostische Nutzen ist jedoch gering ( 4 bis $63 \%)$, da das meist intakte Bronchialepithel den Tumor überzieht. Die präoperative Diagnosestellung eines TC und AC durch eine Biopsie ist nicht immer sinnvoll, da diese stark vaskularisiert sind und es zu starken Blutungen kommen kann ( $\bullet$ Abb.8d) [93-95]. Lebensbedrohliche Blutungskomplikationen sind jedoch selten. Fink et al. fanden in einer Studie mit 587 Patienten nach endobronchialen Biopsien bei flexibler bzw. starrer Bronchoskopie in 15 Fällen $(2,6 \%)$ klinisch relevante Blutungskomplikationen. 11 Patienten (1,9\%) wurden transfusionspflichtig, in 4 Fällen $(0,7 \%)$ war eine Notfallthorakotomie erforderlich [96]. Die Gabe von verdünntem Epinephrin vor und nach einer Biopsie senkt das Blutungsrisiko. Bei makroskopisch eindeutigem Befund und klarer Operationsindikation ergibt sich durch eine Biopsie keine Änderung im therapeutischen Vorgehen, sodass auf eine Biopsie verzichtet werden sollte. Die endobronchiale Sonografie kann genutzt werden, um Bronchialwandinvasionen im Submillimeterbereich vor oder nach einer Endobronchialresektion auszuschließen [97-99], und ist sinnvoll zur Beurteilung des Lymphknotenstadiums sowie im Rahmen der Tumorverlaufskontrolle.

\section{Knochenszintigrafie}

Die Knochenszintigrafie ist besonders sensitiv in der Detektion osteoblastischer Läsionen. Sie ermöglicht die Erfassung des kompletten Skelettsystems und erlaubt eine frühzeitige Diagnosesicherung von Knochenmetastasen, da sie die Veränderungen im Stoffwechsel des Knochens bis zu 18 Monate vor dem konventionellen Röntgen visualisieren kann [100]. Knochenmarksmetastasen kommen hingegen nicht zur Darstellung [101]. 

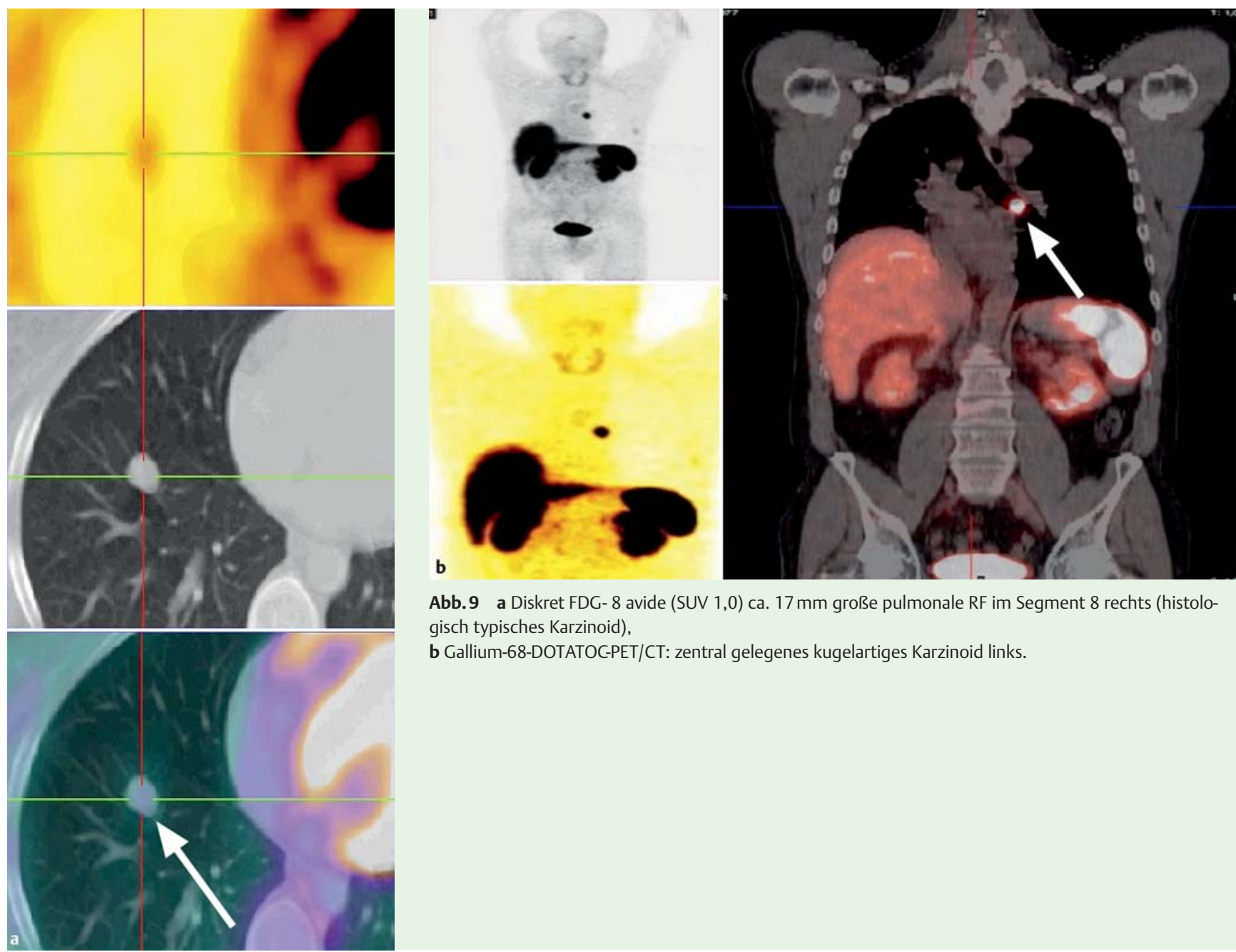

Abb.9 a Diskret FDG- 8 avide (SUV 1,0) ca. 17 mm große pulmonale RF im Segment 8 rechts (histologisch typisches Karzinoid), b Gallium-68-DOTATOC-PET/CT: zentral gelegenes kugelartiges Karzinoid links.

\section{Somatostatin-Rezeptor-Szintigrafie (OctreoScan)}

Bereits 1987 benutzten Krenning et al. radioaktiv markierte Somatostatinanaloga zur bildgebenden Darstellung neuroendokriner Neoplasien [102]. Gut und mäßig differenzierte NEN exprimieren in bis zu $80 \%$ der Fälle Somatostatinrezeptoren. Die Bindung zwischen den Somatostatinrezeptoren und den radioaktiv markierten Somatostatinanaloga (Indium-111 markiertes Pentatreotid) kann mittels planarer sowie Single-Photon-Emissions-Computertomografie (SPECT) und SPECT/CT mit einer Gamma-Kamera visualisiert werden. Eine besonders hohe Affinität des Pentatreotids besteht zu den Somatostatinsubrezeptortypen (SSTR) 2 und 5 [103]. Die ${ }^{111}$ Indium-Octreotidszintigrafie ist überwiegend für den Nachweis von Tumoren $>1,5 \mathrm{~cm}$ geeignet. Sie nimmt einen vorrangigen Stellenwert in der Diagnostik des Primums und der Metastasen neuroendokriner Tumoren ein, ist jedoch nicht völlig spezifisch für diese Tumorentität, da auch Meningiome, Astrozytome, das kleinzellige Lungenkarzinom und Mammakarzinome Somatostatinrezeptoren exprimieren können. Die Sensitivität (80-90\%) ist abhängig vom Somatostatinrezeptorbesatz der NEN. Die Untersuchung kann sich über zwei Tage erstrecken.

\section{${ }^{123}$ lod-Metaiodbenzylguanidin (MIBG)-Szintigrafie}

Diese Untersuchungsmethode sollte nur bei negativer Octreotidszintigrafie zur Anwendung kommen, da sie im Vergleich eine deutlich geringere Sensitivität (<70\% vs. 95\%) aufweist.
Die Anreicherung von ${ }^{123}$ Iod-Metaiodbenzylguanidin in den neuroendokrinen Zellen ist nur mäßig ausgeprägt, sodass aufgrund des niedrigen Tumorkontrastes kleinere Läsionen nicht sicher darstellbar sind [104].

\section{Positronenemissionstomografie mit ${ }^{18} \mathrm{~F}$-FDG}

${ }^{18} \mathrm{~F}$-2-Deoxy-2-Fluor-D-Glukose wird durch Glukosetransporter in die Zelle aufgenommen und durch die Hexokinasereaktion in der Zelle fixiert (metabolic trapping). Zum Nachweis von NEN bedarf es eines ausreichend hohen Glukoseumsatzes der Tumorzellen, was in der Regel an eine erhöhte Proliferations- und Wachstumsrate gekoppelt ist (35-65\% der NEN) [105], die beim TC nicht vorliegt $(\bullet$ Abb.9a). Eine höhere Sensitivität zeigt die FDG-PET/ CT beim Nachweis entdifferenzierter NEN (> 75\%) [106].

\section{Somatostatinrezeptor-PET/CT}

Ga-68-DOTATOC (Edotreotid) bindet an Somatostatinrezeptoren (bevorzugt Subtyp 2 und 5). Die Ga-68-DOTATOC-PET/CT ist zurzeit aufgrund der sehr hohen Empfindlichkeit und des extrem hohen Tumorkontrasts das sensitivste bildgebende Verfahren zum Nachweis neuroendokriner Tumoren. Die Untersuchungszeit beträgt maximal 2 Stunden, während die Octreotidszintigrafie sich über 2 Tage erstrecken kann [106]. Mit der Ga-68-DOTATOC-PET/CT ist die Detektion von Tumoren $<8 \mathrm{~mm}$ möglich [107]. Ein weiterer Vorteil ist die erheblich geringere Strahlenexposition. Die Ga-68-DOTATOC-PET/CT zur Darstellung neuro- 
Tab.5 Indikationen für die Somatostatinrezeptor-PET (SMS-R-PET).

Lokalisation von Primärtumoren und Metastasen
Verlaufskontrolle nach Operation und Rezidivdiagnostik bei Anstieg
spezifischer Tumormarker (z. B. Chromogranin A, Serotonin)
Therapiekontrolle unter Behandlung mit Somatostatinanaloga
(Sandostatin)
Ansprechen auf eine Chemotherapie oder biologische Therapie
Differenzialdiagnose neuroendokriner Tumor versus nicht-endokriner
Tumor (wenn bioptische Klärung nicht möglich)
Indikationsstellung zur Durchführung einer Radiorezeptortherapie
(Intensität der Rezeptorexpression und prätherapeutische Dosimetrie)
und Verlaufskontrolle nach Behandlung

endokriner Neoplasien hat eine Sensivität von 97\% und eine Spezifität von 92\% [108] ( Abb.9b). Sie ist von hoher Bedeutung in der Therapieüberwachung und hilfreich zur Errechnung der benötigten Radioaktivität für die Peptid-Radio-Rezeptor-Therapie (PRRT) ( Tab.5). Ein weiterer spezifischer Marker neuroendokriner Neoplasien der Lunge ist (11)-C-5-HydroxytryptophanPET (5-HTP-PET). ES kann Tumore mit einer Größe von kleiner als $3 \mathrm{~mm}$ im Durchmesser detektieren. Bei 42 Patienten mit NET (davon 6 Patienten mit einer neuroendokrinen Neoplasie der Lunge) konnten, im Vergleich mit der Ga-68-DOTATOC-PET/CT, mittels 11-C-5-HAT-PET 95\% der Tumorläsionen nachgewiesen werden. Es wurden sogar $58 \%$ mehr Läsionen dargestellt als mittels Ga-68-DOTATOC-PET/CT [109]. Von Nachteil ist die kurze Halbwertszeit von ${ }^{11} \mathrm{C}$ mit 20 Minuten [110].

Eine Studie von Irfan et. al ergab im direkten Vergleich zwischen ${ }^{18} \mathrm{~F}$-FDG PET/CT und Ga-68-DOTATATE, dass alle TC eine hohe Aufnahme von Ga-68-DOTATATE (maximal standardized uptake value (SUVmax) $\geq 8,2$ ) zeigten. Vier der Patienten mit einem TC waren nicht bzw. nur gering ${ }^{18} \mathrm{~F}-\mathrm{FDG}$ - avid (SUVmax $=1,7-2,9$ ) $(\bullet$ Abb.9a). AC, LCNEC, SCLC und NSCLC mit neuroendokriner
Differenzierung zeigten vergleichend mit den TC eine höhere ${ }^{18}$ F-FDG Avidität (SUVmax $\geq 11,7$ ) und geringe ${ }^{68} \mathrm{Ga}$-DOTATATE Speicherung (SUVmax $=2,2-2,8$ ). Tumorlets waren weder ${ }^{68} \mathrm{Ga}$ DOTATATE noch ${ }^{18}$ F-FDG avide [111]. Daten aus unserer Arbeitsgruppe bestätigen diese Ergebnisse [150].

\section{Therapie \\ $\nabla$}

siehe $\bullet$ Abb. 10

\section{Chirurgische Therapie}

Eine chirurgische Resektion des Tumors ist die Therapie der ersten Wahl, soweit der Gesamtzustand des Patienten und das Tumorstadium dieses zulässt. Ziel ist die Blockresektion mit vollständiger Entfernung des Tumors unter Erhaltung von möglichst viel funktionellem Lungengewebe. Eine komplette mediastinale Lymphknotenresektion sollte möglichst immer durchgeführt werden. Für zentrale, lokalisierte TC ist eine konservative Resektion, bestehend aus Manschettenresektion, Keil oder Segmentresektion, die bevorzugte Therapieform [112-116]. Beim LCNEC entspricht das Vorgehen dem der nicht kleinzelligen Lungenkarzinome. Die Prognose des LCNEC ist ungünstig. Großzellige neuroendokrine Tumore gelten als sehr aggressiv. Iyoda et al. berichten von einer starken Varianz der 5-Jahres-Überlebensrate zwischen 15 und 57\% [117], mit einem mittleren Überleben von $34 \%$. In einigen Studien erscheint die Prognose des LCNEC vergleichbar mit dem des SCLC. Die Prognose verschlechtert sich bei Lymphknotenbefall. Cardillo et al. und Garcia et al. beschreiben ebenfalls eine signifikante Prognoseverschlechterung bei lymphonodulär metastasierten AC $[118,119]$. Lymphknotenbefall und histologischer Subtyp erscheinen als wichtigste Einflussfaktoren auf die Prognose. Bei Patienten mit einem TC ist ein Lymphknotenbefall nicht sicher mit einer Prognoseverschlechte-

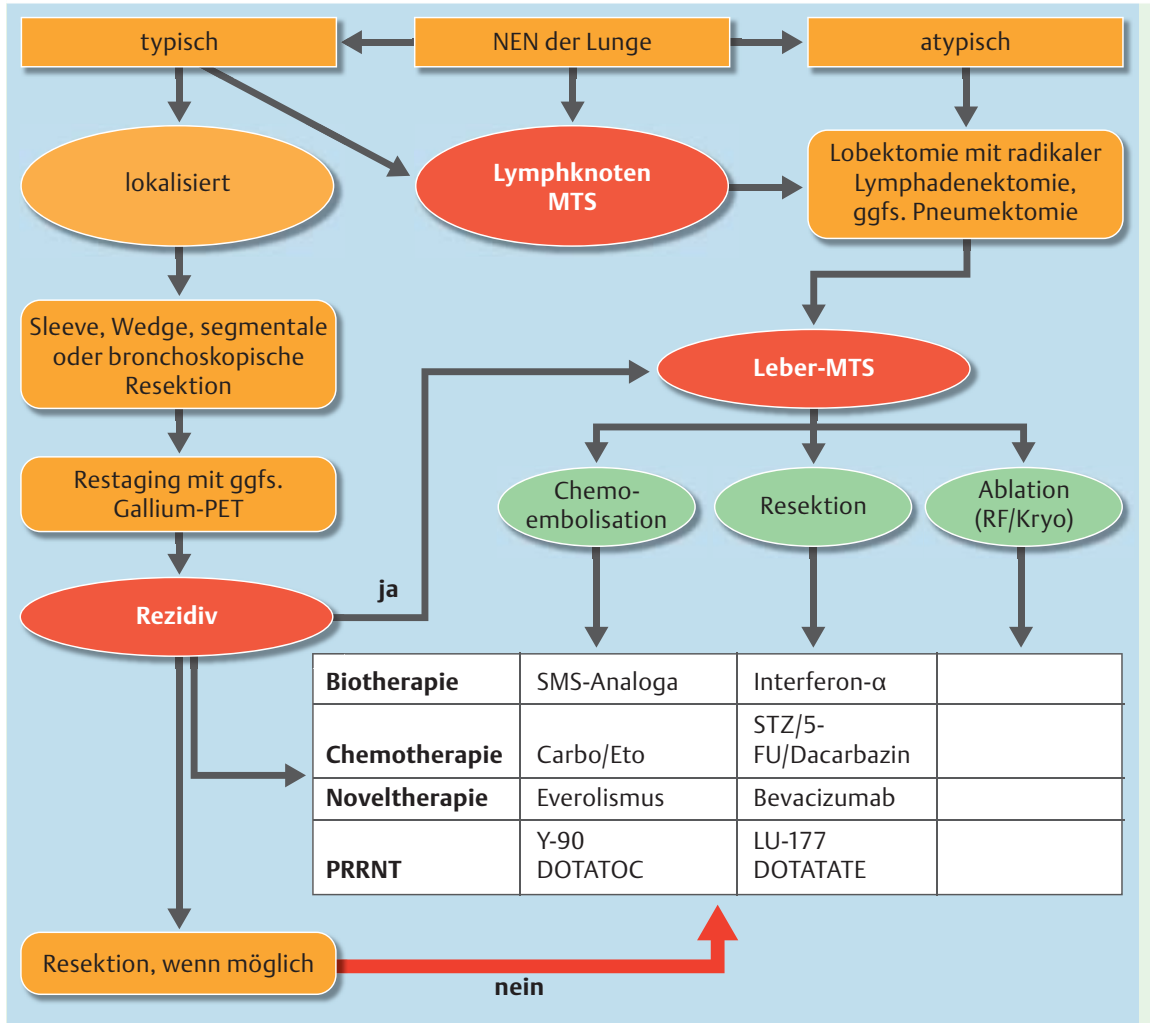

Abb.10 Therapiealgorithmus für Lungenkarzinoide.

NEN: neuroendokrine Neoplasie , MTS: Metastase, SMS: Somatostatin, Carbo: Carboplatin, Eto: Etoposid, FU: Fluorouracil, STZ: Streptozocin, RF: Radiofrequenz, Kryo: Kryotherapie. Modifiziert nach Bjorn I. Gustafsson et al. Cancer 2008; 113: 5-21. 


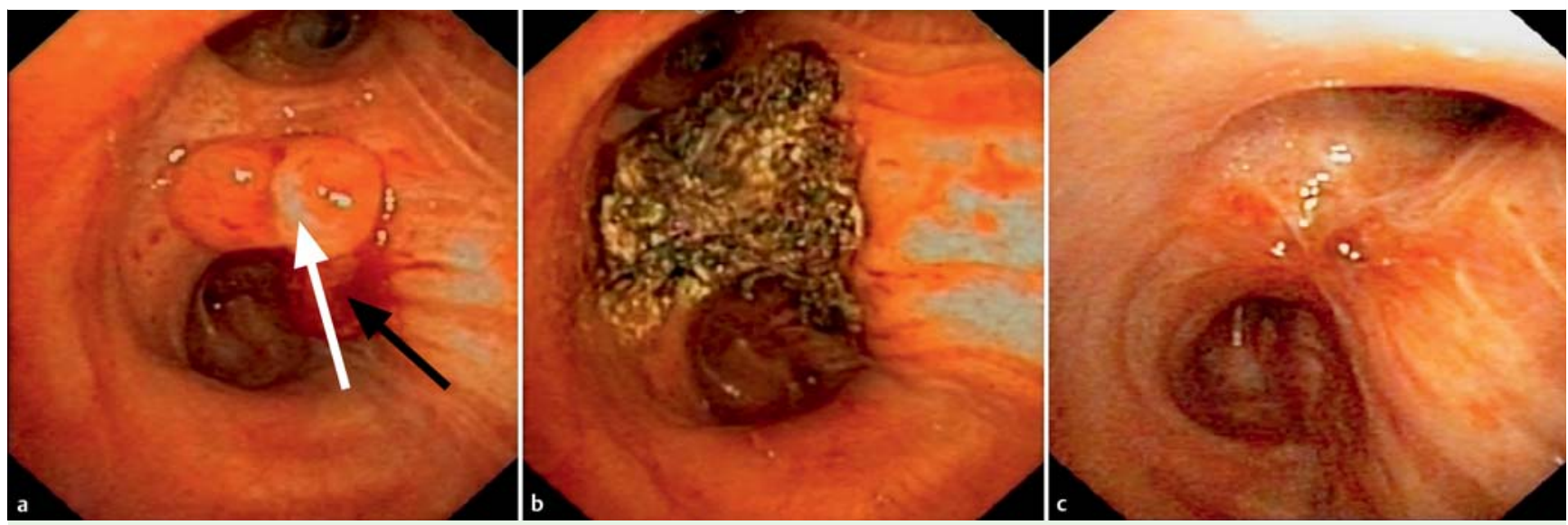

Abb.11 a Endobronchiale Metastase einer neuroendokrinen Neoplasie der Lunge: OL- Karina rechts (weißer Pfeil), Zwischenbronchus (schwarzer Pfeil), b Entfernung der Metastase mit der Kryosonde und anschließende APC-Therapie bei Blutungen nach Abtragung, $\mathbf{c}$ kein Tumorrezidiv 18 Monate nach Resektion.

rung assoziiert $[23,112,120]$. Um ein exaktes Staging und adäquates Tumor-Management zu gewährleisten, ist es unbedingt notwendig, eine radikale bzw. systemische Lymphknotendissektion routinemäßig und unabhängig vom Grad der Tumorresektion anzustreben [121].

\section{Bronchoskopische Therapie}

Eine Alternative bietet in ausgewählten Fällen die bronchoskopische Resektion mittels Hochfrequenzschlinge, Argonbeamer oder Nd-YAG-Laser, insbesondere in Kombination mit der Kryotherapie, soweit keine Metastasen in den mediastinalen Lymphknoten und keine Invasion der Knorpelschichten vorliegen. Laurent Bertoletti et al. evaluierten in einer Studie 18 Patienten mit einer neuroendokrinen Neoplasie der Lunge, die mittels einer endobronchialen mechanischen Resektion und Kryotherapie behandelt wurden. Nur bei einem Patienten konnte nach 7 Jahren ein Tumorrezidiv beobachtet werden [122]. Die Kryotherapie ist nicht assoziiert mit Langzeitkomplikationen wie Bronchialstenosen. Sie stellt eine schonende gewebserhaltende Therapieoption mit guter Prognose dar. Diese Therapiekombination ist vielversprechend, da neuroendokrine Neoplasien gegenüber Kälte sehr sensitiv reagieren und gleichzeitig die Kryotherapie das Knorpelgewebe des Tracheobronchialbaumes nicht zerstört. Die 5-Jahres-Überlebensrate liegt bei über $80 \%$. Die Prognose der TC ist deutlich besser als die der AC nach einer bronchoskopischen Therapie. Heyman Luckraz et al. zeigten an 28 Patienten, die zwischen 1978 und 2004 einer bronchoskopischen Resektion zugeführt wurden, ein rezidivfreies 1-Jahres- bzw. 10-Jahres-Überleben von $100 \%$ bzw. 94\% [123]. Auch Cavaliere et al. [124] berichteten über 150 Patienten mit einem TC, die mit Lasertherapie und mechanischer Tumorabtragung in kurativer Intention behandelt wurden. Nach einem Follow-Up-Zeitraum zwischen einem und 198 Monaten waren alle Patienten rezidivfrei. Drei Patienten wählten eine Thorakotomie nach bronchoskopischer Therapie. Die histologischen Untersuchungen der Operationspräparate zeigten keinen Residualtumor.

Diese Therapieoptionen eignen sich insbesonders bei multimorbiden und funktionell nicht operablen Patienten, denen eine chirurgische Resektion nicht zugemutet werden kann ( $\bullet \mathbf{A b b}$. $11 a-c)$.

\section{Systemische Therapie}

Die Rolle der adjuvanten Therapie nach kompletter Resektion von TC und AC ist nicht eindeutig definiert. Wegen des sehr guten Langzeitüberlebens ist bei TC, auch wenn Lymphknoten befallen sind, eine adjuvante Therapie nach kompletter Resektion nicht indiziert. Bei AC mit mediastinalem Lymphknotenbefall (N2) wird eine adjuvante Therapie in Form einer Chemotherapie, einer Radiotherapie oder einer Kombination aus beiden Therapieoptionen angeraten. Es existieren jedoch keine prospektiven Studien, die den Erfolg adjuvanter Therapieformen für Patienten mit neuroendokrinen Neoplasien der Lunge (typisch oder atypisch) evaluierten. Obwohl sich neuroendokrine Neoplasien als relativ radioresistent erwiesen haben, kann in bestimmten Fällen die Radiotherapie bei lokal fortgeschrittenen, nicht resezierbaren Primärtumoren als palliative bzw. symptomatische Maßnahme sinnvoll sein [125-127].

\section{Chemotherapie}

Der Anteil der Patienten, die im Verlauf metastasieren, liegt zwischen $5 \%$ und $70 \%$. Metastasierungen können sehr spät auftreten, auch noch Jahrzehnte nach Diagnosestellung.

Für die Therapie der TC und AC ist die Verfügbarkeit prospektiver Studien sehr eingeschränkt.

Patienten mit metastasierten neuroendokrinen Neoplasien der Lunge werden oft mit einem Chemotherapieprotokoll, ähnlich dem des SCLC, behandelt (z. B. Cisplatin in Kombination mit Etoposid oder Cisplatin in Kombination mit Paclitaxel). Yamazaki et al. berichten über Ansprechraten der Cisplatin-basierten Chemotherapie großzelliger neuroendokriner Tumoren der Lunge von $50 \%$ [128]. Pulmonale LCNEC zählen zu den aggressiven Tumoren. Diese Tumoren scheinen von einer multimodalen Therapie, auch für das resektable Stadium I, zu profitieren. In einer retrospektiven Analyse von Rossi et al. zeigte sich bei Patienten mit einem LCNEC, die eine adjuvante Platin-Etoposid basierte Chemotherapie erhielten, ein vorteilhafter Verlauf [129]. Patienten mit LCNEC scheinen ebenfalls von Irinotecan- oder einer Paclitaxel-basierten Chemotherapie zu profitieren. In einer japanischen Studie lagen die klinischen Ansprechraten bei Patienten mit LCNEC, die Irinotecan oder Paclitaxel bekommen hatten, bei bis zu 70\% [130]. In einer weiteren Studie aus Schweden wurden insgesamt 31 an einer neuroendokrinen Neoplasie der Lunge erkrankte Patienten behandelt, davon acht Patienten mit Cisplatin/ 
Etoposid. Zwei der Patienten mit einem TC sprachen über einen Zeitraum von sechs bzw. acht Monaten auf die Therapie an. Bei einem Patienten mit einem AC zeigte sich ein stabiler Krankheitsverlauf über sieben Monate. Fünf Patienten entwickelten eine Progression nach 3 bis 4 Monaten. Patienten mit einem Karzinoidsyndrom sprachen seltener auf diese Kombination an als Patienten ohne Karzinoidsyndrom. Es gab keine Korrelation zwischen dem Ansprechen der Behandlung und der Ki-67-Expression. Sieben Patienten bekamen eine Kombination aus Streptozotocin und 5-Fluorouracil. Lediglich ein Patient zeigte einen stabilen Krankheitsverlauf über einen Zeitraum von acht Monaten. Die restlichen sechs Patienten zeigten eine Progression [131].

Eine andere Arbeitsgruppe (Ekeblad et al.) analysierte retrospektiv die Toxizität und Wirksamkeit der Therapie mit Temozolomid bei fortgeschrittenen neuroendokrinen Tumoren. Von den 36 untersuchten Patienten hatten 13 Patienten eine neuroendokrine Neoplasie der Lunge (10 Patienten hatten ein TC und 3 Patienten ein AC). Die Patienten erhielten alle 4 Wochen $200 \mathrm{mg}$ Temozolo$\mathrm{mid} / \mathrm{m}^{2}$ Körperoberfläche über 5 Tage. Das Tumoransprechen erfolgte nach den Response-Evaluation Criteria in Solid Tumors (RECIST-Kriterien) in dreimonatlichen Abständen. Das progressionsfreie Überleben betrug 7 Monate. Vier der Patienten mit einer neuroendokrinen Neoplasie der Lunge zeigten einen stabilen Krankheitsverlauf, 4 Patienten hatten im Beobachtungszeitraum einen Tumorprogress [132].

In einer multizentrischen Phase-II-Studie aus Japan wurde die Kombinationstherapie mit Irinotecan und Cisplatin bei fortgeschrittenen LCNEC untersucht. Eingeschlossen wurden initial 44 Patienten. Nach histologischer Nachuntersuchung hatten aber nur 30 Patienten ein LCNEC (10 Patienten hatten ein SCLC und ein Patient ein NSCLC mit neuroendokriner Aktivität). Die Patienten bekamen Irinotecan $\left(60 \mathrm{mg} / \mathrm{m}^{2}\right.$, Tag 1, 8 und 15) und Cisplatin $\left(60 \mathrm{mg} / \mathrm{m}^{2}\right.$, Tag 1) alle 4 Wochen für insgesamt 4 Zyklen. Die Ansprechrate lag bei $46,7 \%$. Das mediane progressionsfreie Überleben betrug 5,9 Monate und das mediane Überleben 12,6 Monate [133].

\section{Somatostatinanaloga}

Die derzeit für die Therapie funktionell aktiver NEN zugelassenen Somatostatinanaloga Octreotid und Lanreotid binden vor allem an den Somatostatinrezeptor SSTR2. Eine Weiterentwicklung ist das SOM230 (Pasireotide), das an alle Somatostatinrezeptoren (außer Typ 4) bindet und möglicherweise verbesserte antisekretorische Eigenschaften besitzt ( $\bullet$ Tab.6). Somatostatinanaloga werden vor allem zur Symptomkontrolle bei funktionellen NET eingesetzt. Etwa $60 \%$ der Patienten zeigen diesbezüglich einen Nutzen [134-136].

Die antisekretorische Wirkung von Somatostatinanaloga entsteht durch die Bindung an die Somatostatinrezeptorsubtypen (SSTR) 2 und 5 ausgelöste Inhibition von cAMP. Hierdurch kommt es zur Reduktion des Kalziumeinstroms und konsekutiver Hemmung der Exozytose und damit der Freisetzung biogener Amine. Somatostatinanaloga führen zudem zu einem Zellzyklusarrest in der G1-/S-Phase und induzieren über die SSTR2 und 3 die Apoptose. Neueste Daten legen nahe, dass Somatostatinanaloga über Endothelzellen direkte und über die Hemmung der Ausschüttung von Wachstumsfaktoren wie IGF-1 und VEGF indirekte Wirkungen auf die Tumorangiogenese haben. In einer multizentrischen, placebokontrollierten, doppelverblindeten Phase-IIIB-PROMIDStudie aus dem Jahre 2009 wurde ein medianes progressionsfreies Überleben von 14 versus 6 Monaten bei Patienten gesehen, die einmal monatlich mit $30 \mathrm{mg}$ Ocreotide long-acting release (LAR)
Tab. 6 Somatostatinrezeptoren und ihre Funktionen.

\begin{tabular}{|lccccc|}
\hline Funktion & SSTR1 & SSTR2 & SSTR3 & SSTR4 & SSTR5 \\
\hline Antisekretorisch & & + & + & - & + \\
\hline Antiangionic & & + & + & - & + \\
\hline Antiproliferativ & + & + & + & - & + \\
\hline Apoptose-Induktion & + & + & + & - & \\
\hline
\end{tabular}

intramuskulär anstatt mit Placebo behandelt wurden und wenige kleine Lebermetastasen aufwiesen. Patienten mit einem NEN der Lunge wurden ausgeschlossen [137].

\section{Interferontherapie}

Der antisekretorische Effekt von Interferon- $\alpha$ beruht unter anderem auf der Inhibition der Chromogranin-A-Transkription auf zellulärer Ebene [138].

Faiss et al. untersuchten in einer multizentrischen Studie prospektiv den antiproliferativen Effekt von Lanreotid, Interferon- $\alpha$ und die Kombination beider Präparate bei metastasierten gastroenteropankreatischen NEN. Die Patienten erhielten entweder dreimal täglich $1 \mathrm{mg}$ Lanreotid subkutan oder dreimal täglich $5 \times 10^{6}$ I.E. Interferon- $\alpha$ oder eine Kombination aus Lanreotid und Interferon- $\alpha$. Die Studie zeigte vergleichbare antiproliferative Effekte in der Behandlung metastasierter gastroenteropankreatischer NEN von Somatostatinanaloga, Interferon- $\alpha$ oder ihrer Kombination unabhängig von der Funktionalität des Tumors [139]. Auch Arnold et al. konnten bei 21 Patienten mit einem fortgeschrittenen metastasierten gastroenteropankreatischen NEN die antiproliferative Effektivität der Kombinationstherapie von Interferon- $\alpha$ und Somatostatinanaloga zeigen [140]. In beiden Studien waren neuroendokrine Tumoren des Vorderdarms enthalten, eine Differenzierung in Lunge oder Duodenum beziehungsweise Pankreas erfolgte jedoch nicht. Aufgrund der starken unerwünschten Arzneimittelwirkungen sollte die Interferontherapie nur bei unzureichender Wirkung der Somatostatinanaloga erfolgen. Eine geplante multizentrische dreiarmige Phase-2-(LUNA)Studie wird die Wirksamkeit und Sicherheit der Therapie mit einem Somatostatinanalogon (Pasireotid LAR $60 \mathrm{mg}$ i.m. alle 28 Tage), Everolimus (10 mg p.o. täglich) als Monotherapie und die Kombination (Pasireotid LAR $60 \mathrm{mg}$ i. m. alle 28 Tage und Everolimus $10 \mathrm{mg}$ p.o. täglich) bei Patienten mit Lungen- bzw. Thymus NEN vergleichen.

\section{Bevacizumab}

In einer im 2008 veröffentlichten randomisierten Phase-II-Studie wurde die Therapie mit Bevacizumab (BEV) in Kombination mit pegyliertem (PEG) Interferon alfa-2b an Patienten mit einem metastasierten oder nichtoperablen neuroendokrinen Tumor evaluiert [141].

Aufgenommen wurden 44 Patienten. Die Patienten erhielten über 18 Wochen Octreotid in Kombination mit Bevacizumab oder PEG-Interferon alfa-2b. Bei mittels Computertomografie dokumentiertem Progress (PD) bzw. nach Ablauf der 18 Wochen erhielten die Patienten Bevacizumab und PEG-Interferon alfa-2b. Das progressionsfreie Überleben (PFS) lag bei 95\% nach 18 Wochen der Monotherapie mit Bevacizumab im Vergleich zu 68\% in dem PEG-Interferon-Arm. Funktionelle CT-Aufnahmen zeigten einen signifikanten Rückgang in der Blutversorgung, des Blutvolumens sowie der Permeabilität der Oberfläche des Tumors unter der Therapie mit Bevacizumab. In dieser Studie waren NEN der Lunge mit nur 4 eingeschlossenen Patienten unterrepräsentiert, 

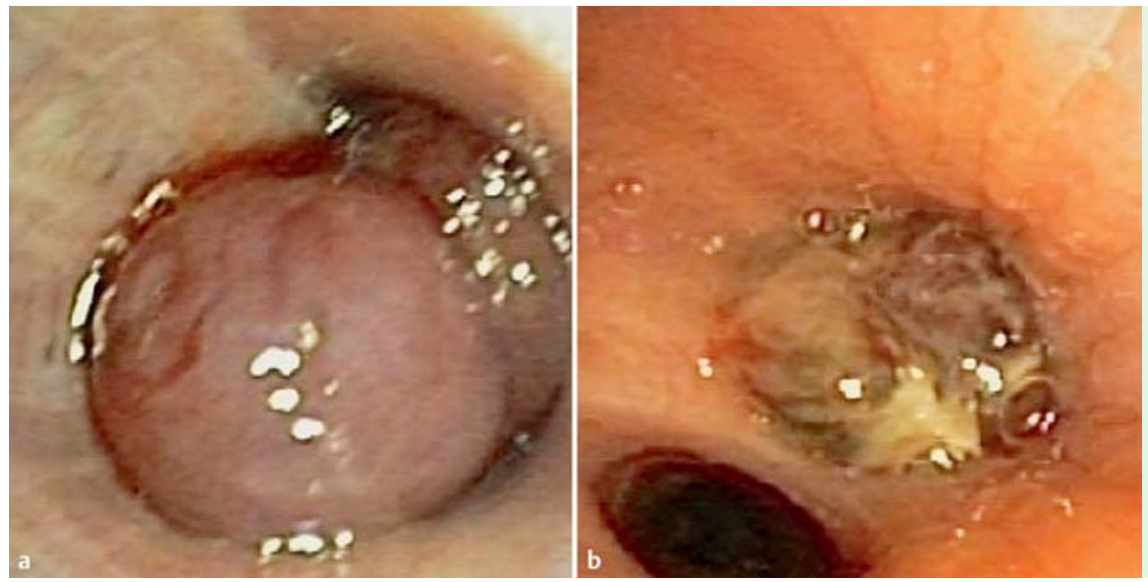

Abb.12 a Neuroendokrine Neoplasie der Lunge vor Therapieeinleitung mit Everolimus, b 8 Wochen nach Therapieeinleitung mit Everolimus - deutliche Schrumpfung des Tumors mit Teilrekanalisation des linken Unterlappens.

daher ist eine Aussage zum Ansprechen bei Lungen NEN nicht möglich.

\section{Everolimus}

In der multinational randomisierten Phase-III-RADIANT-2-Studie wurden 429 Patienten mit einem fortgeschrittenen NET evaluiert. 44 Patienten hatten als Primärtumor eine NEN der Lunge (11\%) [142]. In einer kürzlich publizierten Subgruppenanalyse dieser Phase-III-Studie lag das mediane progressionsfreie Überleben der Patienten mit einer NEN der Lunge, ohne Berücksichtigung vorausgegangener Therapien, zu Gunsten des EverolimusArmes $(10 \mathrm{mg} / \mathrm{d})+$ Ocreotid-LAR (30 mg i.m. alle 4 Wochen) bei 13,63 Monaten vs. 5,59 Monaten im Placebo+Ocreotid-LARArm [143]. Aufgrund der Ergebnisse dieser Subgruppenanalyse sollte die Kombinationstherapie von Octreotid LAR mit Everolimus in der Behandlung fortgeschrittener TC und AC in Betracht gezogen werden ( $\bullet$ Abb.12a,b).

\section{Sunitinib}

Sunitinib wurde ebenfalls in der Behandlung von fortgeschrittenen NEN erprobt. Eine Phase-2-Studie bewertete die Wirksamkeit und Sicherheit von Single-Agent Sunitinib. Insgesamt wurden 41 Patienten mit einer neuroendokrinen Neoplasie aufgenommen, 14 dieser Patienten hatten eine NEN der Lungen oder des Magens. Eine partielle Remission wurde bei 2,4\% der Patienten beobachtet, $82,9 \%$ der Patienten zeigten einen stabilen Krankheitsverlauf. Die mediane Zeit bis zum Tumorprogress betrug 10,2 Monate [144]. Da NEN der Lunge nicht explizit aufgeführt wurden, ist hier eine Aussage über den Therapieeffekt nicht sicher möglich.

In einer multinationalen placebokontrollierten Phase-III-Studie wurde Sunitinib in der Behandlung von NEN des Pankreas erprobt [145]. 171 Patienten wurden randomisiert und erhielten entweder $37,5 \mathrm{mg}$ Sunitinib täglich oder ein Placebopräparat. Die Studie wurde vorzeitig abgebrochen, nachdem in der Placebogruppe eine höhere Mortalität und häufiger unerwünschte Nebenwirkungen sowie ein schnellerer Tumorprogress dokumentiert werden konnten. Das mittlere progressionsfreie Überleben lag in der Sunitinib-Gruppe bei 11,4 Monaten versus 5,5 Monate in der Placebogruppe. In der Sunitinibgruppe verstarben 9 Patienten (10\%), in der Placebogruppe 21 (25\%).

\section{Peptid-Rezeptor-Radionuklid-Therapie (PRRT)}

Die Expression von Somatostatinrezeptoren auf den neuroendokrinen Tumorzellen ist die Grundlage der Peptidrezeptor-vermittelten Radionuklid-Therapie (PRRT) oder kurz Radiorezeptortherapie. Bei diesem Verfahren wird über einen Chelator (=DOTA) ein Betastrahlen emittierendes Therapienuklid an ein Somatostatinanalogon gebunden (Octreotate=DOTA-TATE oder Tyrosin-Octreotid=DOTA-TOC) ( Abb. 13). Je nach Tumor- bzw. Metastasengröße wird ${ }^{90}$ Yttrium (Betastrahler mit einer Reichweite von ca. 12 mm im Gewebe) oder ${ }^{177}$ Lutetium (Betastrahler mit geringer Reichweite von ca. $2 \mathrm{~mm}$ ) als Therapienuklid eingesetzt. Die Radiorezeptortherapie stellt eine sichere und effektive Therapieoption für Tumoren mit adäquatem Rezeptorbesatz dar ( Abb. 14) [146, 147]. Im Falle eines nicht-operablen, metastasierten Somatostatinrezeptor-positiven neuroendokrinen Neoplasmas führt eine rezeptorvermittelte Radiotherapie mit ${ }^{90}$ Yttrium DOTATOC bei mehr als der Hälfte der Patienten zur Symptombesserung. Zur Anwendung kommen entweder ${ }^{90}$ Yttrium oder ${ }^{177}$ Lutetium markierte Somatostatinanaloga. Mit DOTA0Tyr3octreotate konnten in Studien Remissionsraten von bis zu 50\% dokumentiert werden. Die mediane Wirksamkeit der Therapie betrug bei Patienten, die mit DOTAOTyr3octreotate therapiert wurden, 30 Monate und bei Patienten, die mit ${ }^{90}$ Y-DOTA0 beziehungsweise mit Tyr3octreotide oder ${ }^{177} \mathrm{Lu}$-therapiert wurden, jeweils 36 Monate [148]. Drei Patienten mit einem histologisch gesicherten SCLC, die eine Therapie mit Lu-177DOTA0Tyr3octreotate erhielten, verstarben innerhalb von 5 Monaten nach erfolgter erster PRRT [149].

Indikationen und Kontraindikationen für PRRT sind in $\bullet$ Tab.7 und Tab. 8 dargestellt. Aufgrund potenzieller Nebenwirkungen, die besonders die Nierenfunktion und das blutbildende Knochenmark betreffen, ist es wichtig, die Patientengruppen genau zu definieren, die mit hoher Wahrscheinlichkeit von einer Therapie profitieren. Die Menge der applizierten Radioaktivität („Therapiedosis“) hängt dabei von der Somatostatinrezeptor-Expression, der Tumorlast, der Nierenfunktion und dem hämatologischen Status ab. Die Toxizität der PRRT kann durch mehrfache Applikation kleinerer Mengen an Radioaktivität (anstatt einer großen Menge in einer Sitzung) abgemildert beziehungsweise weitgehend vermieden werden („Bad Berkaer PRRT-Konzept“) [150]. Zu den akuten Nebenwirkungen der Radiorezeptortherapie zählen Symptome wie allgemeine Müdigkeit, Kopfschmerzen sowie Übelkeit und Erbrechen. Zudem kann es zu einer Zunahme der Flushsymptomatik kommen, die über Tage anhalten kann. Infolge des Tumorzelluntergangs und der dadurch bedingten 


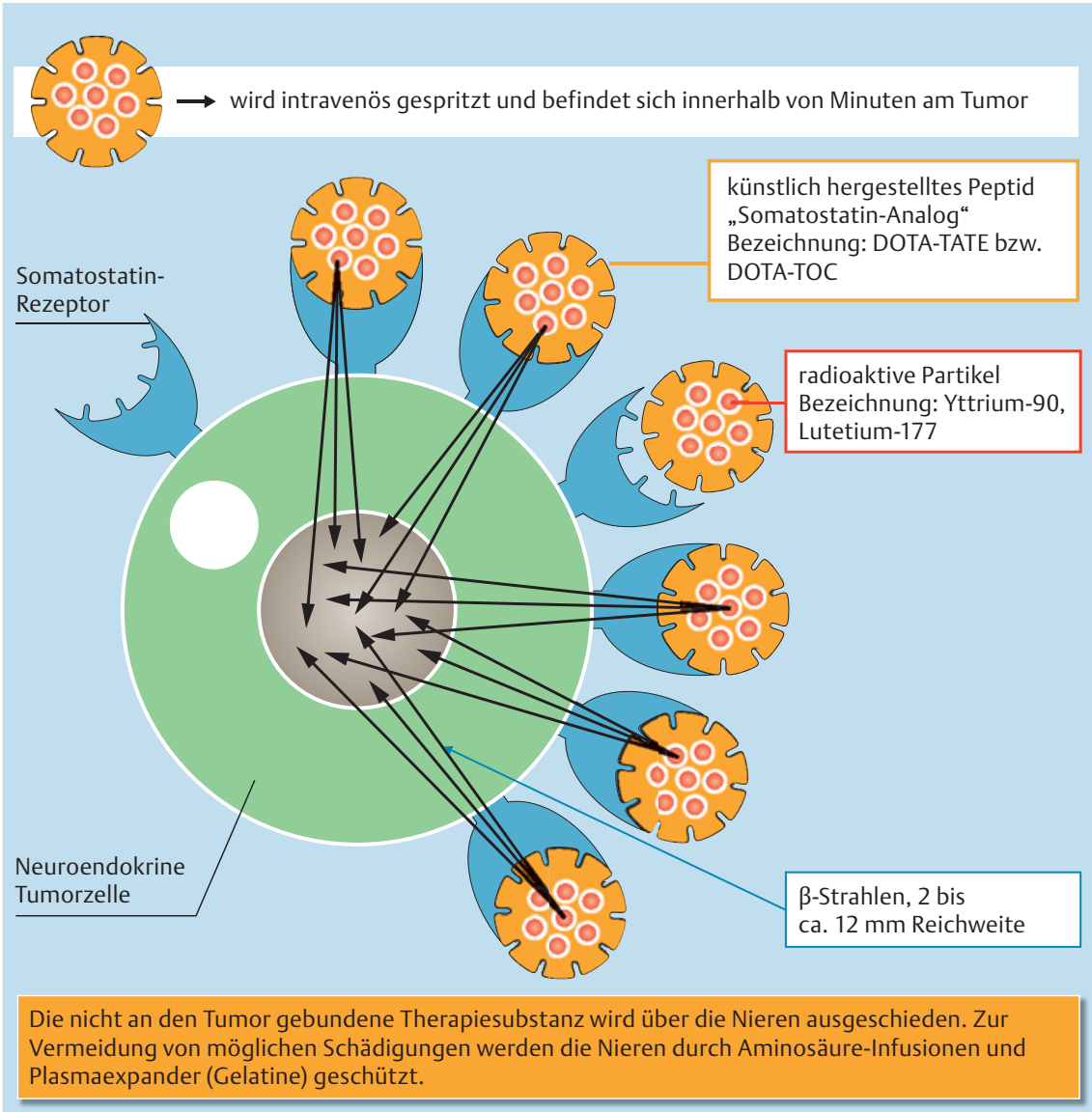

Abb.13 Wirkungsweise der Peptid-RezeptorRadionuklid-Therapie (PRRT).
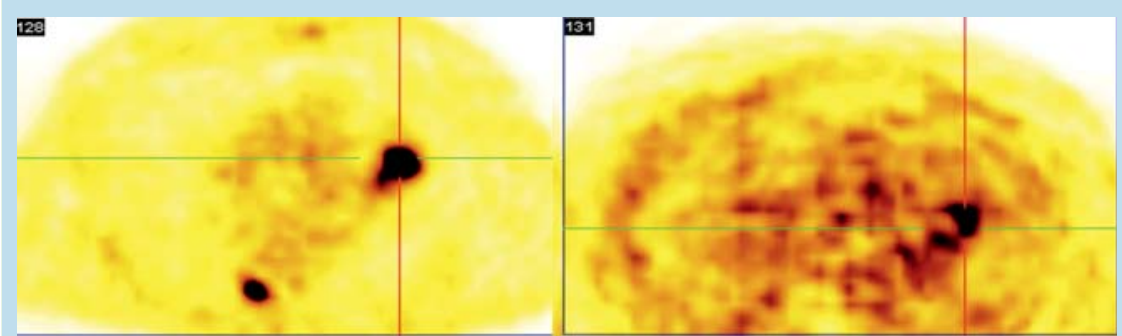

Abb.14 Verlauf unter Radiorezeptortherapie.
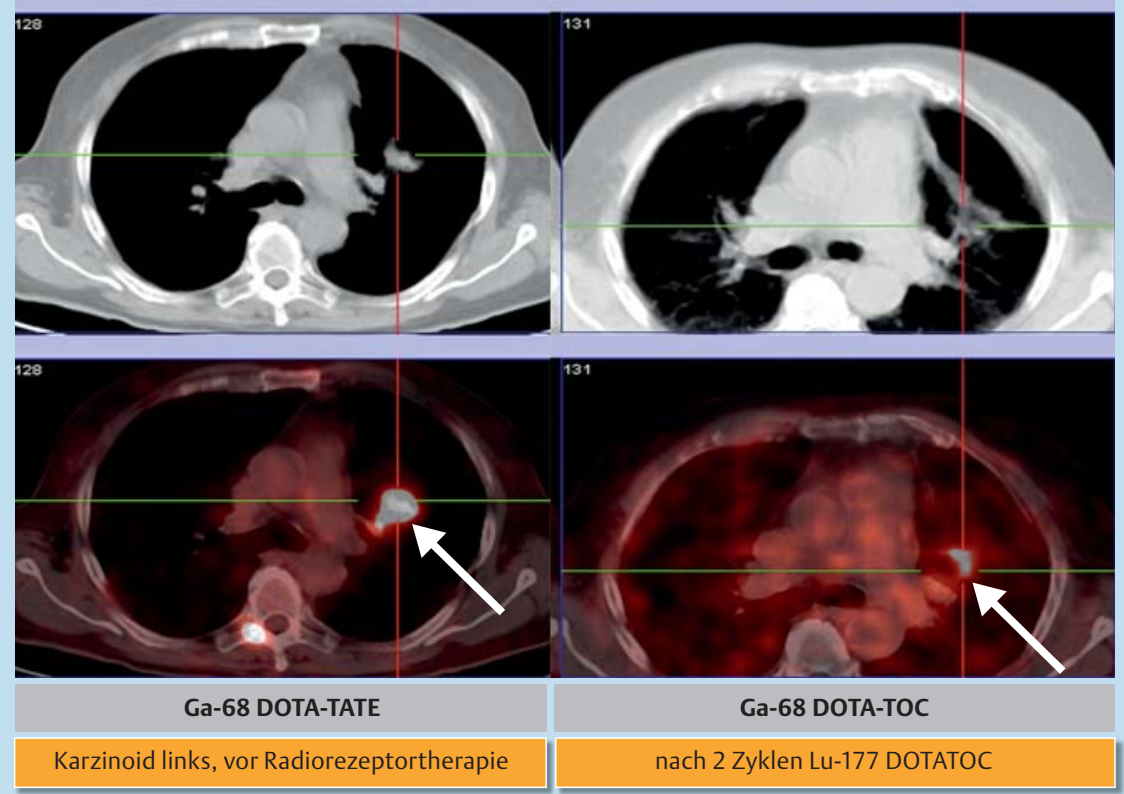
Tab.7 Allgemeine Kriterien für die Peptid-Rezeptor-Radiotherapie.

\begin{tabular}{|c|c|}
\hline Klinische Kri & Molekularbiologische Kriterien \\
\hline \multirow{3}{*}{$\begin{array}{l}\text { Inoperable Karzinoide mit multi- } \\
\text { plen Metastasen und einer durch } \\
\text { den Hormonexzess bedingten, die } \\
\text { Lebensqualität stark beeinflussen- } \\
\text { den Symptomatik, die auf die übli- } \\
\text { chen medikamentösen Maßnah- } \\
\text { men nicht anspricht. }\end{array}$} & $\begin{array}{l}\text { Der Tumor muss eine ausreichende } \\
\text { Menge und Dichte an Peptidrezep- } \\
\text { toren exprimieren. }\end{array}$ \\
\hline & $\begin{array}{l}\text { vorzugsweise h } \\
\text { und hohe Strahl }\end{array}$ \\
\hline & $\begin{array}{l}\text { Der exprimierte Subtyp muss eine } \\
\text { hohe Affinität an den Radioliganden } \\
\text { aufweisen. }\end{array}$ \\
\hline $\begin{array}{l}\text { Kein Erfolg mit etablierten Thera- } \\
\text { pien, rasch proliferierende NET } \\
\text { (Ki-67 > } 10 \% \text { ) mit ausgeprägtem } \\
\text { Somatostatinrezeptorbesatz nach } \\
\text { Versagen der Chemotherapie }\end{array}$ & $\begin{array}{l}\text { Tumorlokalisation vorzugsweise } \\
\text { außerhalb der Blut-Hirn-Schranke } \\
\text { (alternative Anwendung für Tumo- } \\
\text { ren des zentralen Nervensystems) }\end{array}$ \\
\hline
\end{tabular}

Modifiziert nach Jean Claude Reubi et al. Candidates for Peptide Receptor Radiotherapy Today and in the Future. J Nucl Med 2005; 46: 67S-75S.

Tab. 8 Kontraindikationen der Peptid-Rezeptor-Radionuklid-Therapie (PRRT).

\begin{tabular}{|c|}
\hline - eine andere maligne Zweiterkrankung \\
\hline $\begin{array}{l}\text { - eingeschränkte Nierenfunktion mit pathologischer 99mTc-DTPA- } \\
\text { oder 99mTC-MAG3-Szintigrafie bzw. erhöhten Kreatinin- oder Harn- } \\
\text { stoffwerten }\end{array}$ \\
\hline - Knochenmarksdepression nach Chemotherapie \\
\hline $\begin{array}{l}\text { - schlecht differenzierte neuroendokrine Tumoren mit hohem } \\
\text { Proliferationsindex }\end{array}$ \\
\hline $\begin{array}{l}\text { - Erythrozyten }<3 \text { Mio und/oder Leukozyten }<3500 / \mu \text { l und/oder } \\
\text { Thrombozyten }<80 \text { Tsd/ } \mu \text { l }\end{array}$ \\
\hline - Patienten mit Karnofsky-Index $<50 \%$ \\
\hline - nicht beherrschbare Inkontinenz \\
\hline - rasch proliferative Tumoren (Ki-67>10\%) vor Chemotherapie \\
\hline $\begin{array}{l}\text { - über einen Zeitraum von mindestens } 6 \text { Monaten nicht wachsende } \\
\text { Tumoren mit durch Biotherapie beherrschbarer Symptomatik }\end{array}$ \\
\hline $\begin{array}{l}\text { - Intervall<6 Wochen zu vorausgegangener Strahlen- oder Chemo- } \\
\text { therapie }\end{array}$ \\
\hline
\end{tabular}

Hormonausschüttung kann es in seltenen Fällen zu Atem- und Kreislaufbeschwerden kommen. Extrem selten treten allergische Reaktionen unter der Verabreichung der Nephroprotektiva auf. Vor allem bei Patienten mit Knochenmetastasen werden Blutbildveränderungen im Sinne einer isolierten Anämie bzw. Panzytopenie beobachtet, daher sind postinterventionelle Blutbildkontrollen sehr wichtig. Bei wiederholter Therapie kann es zu einer Einschränkung der Nierenfunktion kommen. In einer retrospektiven Studie aus der Zentralklinik Bad Berka wurde die Wirksamkeit der Peptid-Rezeptor-Radionuklid-Therapie (PRRT) als Erstoder Zweitlinientherapie als Behandlungsoption fortgeschrittener metastasierter gut differenzierter NEN der Lunge bewertet (nichtveröffentliche Daten). Insgesamt wurden 43 Patienten (29 Männer, 14 Frauen, Durchschnittsalter 60 Jahre) evaluiert. 11 Patienten hatten ein TC und 32 Patienten ein AC. 26 Patienten hatten sich vor PRRT einer chirurgischen Resektion unterzogen, zwei Patienten waren initial nicht operabel und konnten nach PRRT operiert werden. Eine Chemotherapie wurde bei 12 der eingeschlossenen Patienten in der Vorgeschichte durchgeführt. Bei 31 Patienten erfolgte die PRRT als Erstlinien-Behandlung. Die kumulative verabreichte Aktivität lag zwischen 3 und 40,6 (1-6 Zyklen) Gigabecquerel (GBq) Lu-177 oder Y-90 markierten DOTATATE/DOTATOC. Das Ansprechen der Therapie wurde mittels MRT des Abdomens, Kontrastmittel-Computertomografie des Thorax sowie Ganzkörper Ga-68 DOTATOC PET/CT evaluiert.

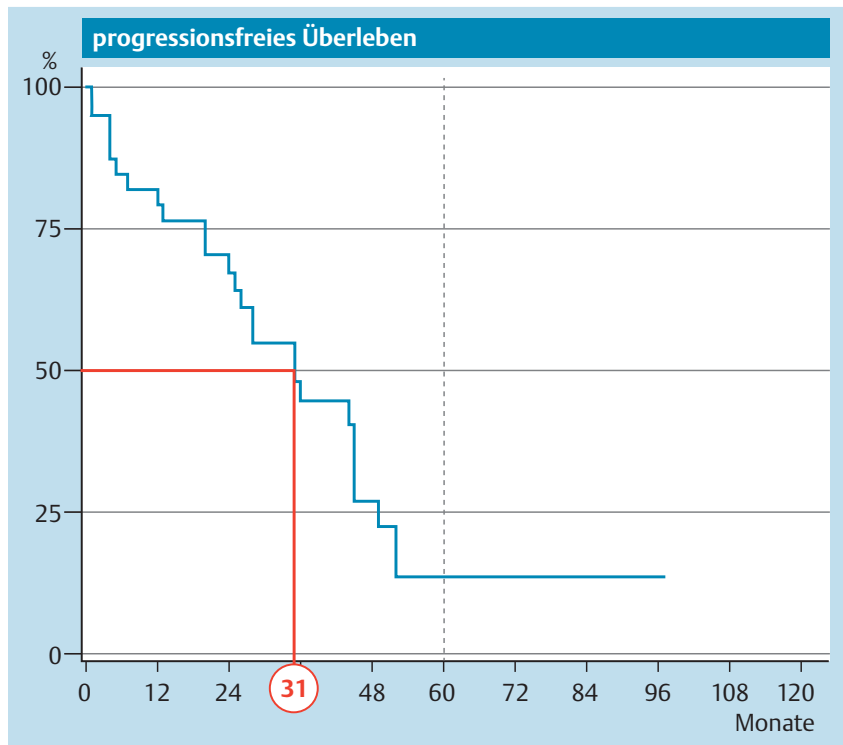

Abb.15 Retrospektive Analyse des Überlebens nach Peptid-RezeptorRadionuklid-Therapie bei Patienten mit fortgeschrittenen, gut differenzierten NEN der Lunge $(n=43)$.

Ein Patient hatte eine komplette Remission (2\%), 5 (12\%) Patienten eine partielle Remission, 14 (33\%) Patienten einen stabilen Krankheitsverlauf, und 23 Patienten (53\%) zeigten eine Tumorprogression unter PRRT. Das mediane progressionsfreie Überleben betrug 31 Monate ( $\bullet$ Abb. 15). Verglichen mit den zur Verfügung stehenden Therapieoptionen stellt die PRRT somit eine effektive Erst- bzw. Zweitlinientherapie fortgeschrittener gut differenzierter NEN der Lunge dar. Bei funktionell und vom Tumorstadium her operablen Patienten sollte die chirurgische Resektion jedoch immer an erster Stelle stehen.

\section{Prognose}

Neuroendokrine Tumoren der Lunge stellen ein Spektrum des klinischen Verhaltens von indolenten (TC) bis rasch tödlichem Verlauf dar (SCLC). TC haben eine sehr gute Prognose, denn nur $1-2 \%$ der neuroendokrinen Neoplasien der Lunge rezidivieren. Die 5-Jahres-Überlebensrate liegt zwischen 75 und 100\% [151, 152]. Daher ist das TC als low-grade Malignität definiert. AC sind deutlich aggressiver als TC, mit höherer Frequenz von Lymphknotenmetastasen (etwa 50\%) und Fernmetastasen (ca. 20\%). Sie haben eine 5-Jahres-Überlebensrate von nur ca. 30-60\% [28]. Am anderen Ende des klinischen Spektrums steht das SCLC, bei dem das Überleben in Monaten angegeben wird. Die 5-JahresÜberlebensrate liegt bei 5\% [153]. Die meisten Patienten haben bei Diagnosestellung oft stark ausgeprägte lokoregionäre Lymphknotenmetastasen, und zwei Drittel der Patienten haben Fernmetastasen (Gehirn, Leber, Nebennieren, Knochen und Knochenmark) [154]. Die Prognose des LCNEC ist ungünstig. Großzellige neuroendokrine Tumore gelten als sehr aggressiv. Iyoda et al. gaben eine starke Varianz der 5-Jahres-Überlebensrate von 15 bis $57 \%$ an, [117], mit einem mittleren Überleben von $34 \%$. In einigen Studien erscheint die Prognose des LCNEC vergleichbar mit dem des SCLC. Die Prognose verschlechtert sich, wenn Lymphknoten befallen sind, was nicht für TC zutrifft, wie Filosso et al. feststellen $[23,112]$. Auch Schreurs, der 93 Patienten mit ausschließlich TC untersuchte, konnte keinen Zusammenhang 


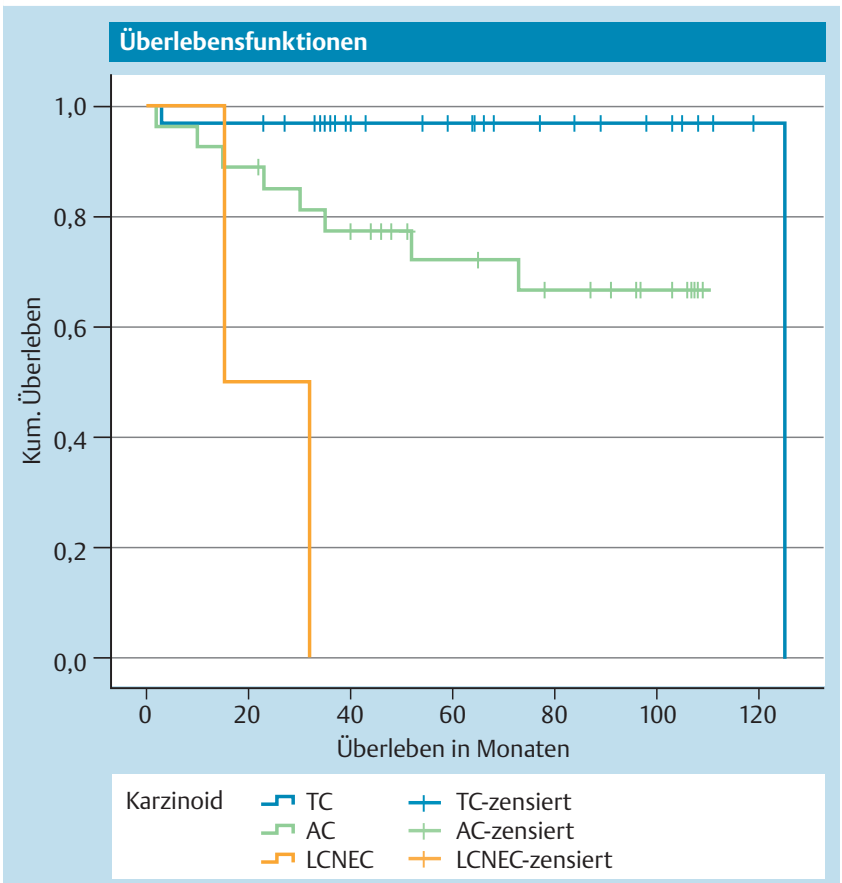

Abb.16 Überlebenskurven der operierten Patienten mit einer neuroendokrinen Neoplasie der Lunge in Abhängigkeit von der Histologie ( $n=61$ Patienten).

nachweisen [120]. Jedoch fanden Garcia et al. und Filosso et al. signifikante Unterschiede zwischen dem Lymphknotenbefall der TC und AC [119]. Lymphknotenbefall und histologischer Subtyp erscheinen hierbei als wichtigste Einflussfaktoren auf die Prognose. Cardillo et al. berichteten über eine signifikant niedrigere 5-Jahres-Überlebensrate bei Patienten mit AC und N1-Befall im Vergleich zu Patienten mit TC und N1-Befall. Auch die 5-JahresÜberlebensrate von Patienten mit einem AC und N2-Beteiligung war signifikant niedriger in dieser Studie [118]. Um ein exaktes Staging und adäquates Tumor-Management zu gewährleisten, ist es notwendig, eine radikale oder systemische Lymphknotendissektion routinemäßig und unabhängig vom Grad der Tumorresektion durchzuführen [121,151].

Daten von 61 Patienten aus der Zentralklinik Bad Berka (nichtveröffentliche Daten) zeigen retrospektiv eine gute Prognose für das TC. Nur 6,3\% der 32 Patienten verstarben im Verlauf. Zwanzig Prozent der eingeschlossenen 27 Patienten mit einem AC verstarben nach durchschnittlich 30 Monaten. Beide Patienten mit einem LCNEC verstarben 23 bzw. 24 Monate nach Diagnosestellung ( $\bullet$ Abb. 16).

\section{Interessenkonflikt}

$\nabla$

Y. Sayeg, M. Sayeg, R. P. Baum, H. R. Kulkarni, N. Presselt, I. Mäder, A. Kunze und J. Sänger geben an, dass kein Interessenkonflikt besteht.

D. Hörsch hat Honorare und Reisekostenerstattungen von den Firmen Pfizer, IPSEN, Novartis und Lexicon Pharmaceuticals Inc. erhalten. Eine Unterstützung von Studien erhält er von Novartis, IPSEN, Covidien, Eckart, Ziegler, ITG und MSD Nordion.

R. Bonnet hat Honorare für Beratertätigkeit, Vorträge sowie Reisekostenzuschüsse von der Firma Novartis erhalten.
Institute

${ }^{1}$ Klinik für Pneumologie der Zentralklinik Bad Berka GmbH

2 Zentrum für Neuroendokrine Tumore Bad Berka - ENETS Center of Excellence und Klinik für Innere Medizin, Gastroenterologie und Endokrinologie

${ }^{3}$ Klinik für Molekulare Radiotherapie, Zentrum für Molekulare Bildgebung (PET/CT)

${ }^{4}$ Klinik für Thorax- und Gefäßchirurgie der Zentralklinik Bad Berka GmbH

${ }^{5}$ Institut für Pathologie in Bad Berka

\section{Literatur}

1 Waxman J. Molecular Endocrinology of Cancer. Volume 1, Part 2, Cambridge University Press; 1996: 318

2 Williams ED, Sandler M. The classification of carcinoid tumors. Lancet 1963; $1: 238-239$

3 Travis WD, Linnoila RI, Tsokos MG et al. Neuroendocrine tumors of the lung with proposed criteria for large-cell neuroendocrine carcinoma: an ultrastructural, immunohistochemical, and flow cytometric study of 35 cases. Am J Surg Pathol 1991; 15: 529-553

4 Borges M, Linnoila RI, van de Velde HJ et al. An achaete-scute homologue essential for neuroendocrine differentiation in the lung. Nature 1997; 386: 852-855

5 Ito T, Nogawa H, Udaka $\mathrm{N}$ et al. Development of pulmonary neuroendocrine cells of fetal hamster in explant culture. Lab Invest 1997; 77 : 449-457

6 Montuenga LM, Guembe L, Burrell MA et al. The diffuse endocrine system: from embryogenesis to carcinogenesis. Prog Histochem Cytochem 2003; 38: 155-272

7 Cutz E, Speirs $V$, Yeger $H$ et al. Cell biology of pulmonary neuroepithelial bodies - validation of an in vitro model. I. Effects of hypoxia and $\mathrm{Ca} 2+$ ionophore on serotonin content and exocytosis of dense core vesicles. Anat Rec 1993; 236: $41-52$

$8 \mathrm{Fu} X W$, Wang $D$, Nurse CA et al. NADPH oxidase is an 02 sensor in airway chemoreceptors: evidence from $\mathrm{K}+$ current modulation in wildtype and oxidase-deficient mice. Proc Natl Acad Sci U S A 2000; 97: 4374-4379

9 Sorokin SP, Ebina M, Hoyt RF Jr. Development of PGP 9.5- and calcitonin gene-related peptide-like immunoreactivity in organ cultured fetal rat lungs. Anat Rec 1993; 236: $213-225$

10 Hoyt RFJr, Sorokin SP, McDowell EM et al. Neuroepithelial bodies and growth of the airway epithelium in developing hamster lung. Anat Rec 1993; 236: 15-22

11 Emanuel RL, Torday JS, Mu Q et al. Bombesin-like peptides and receptors in normal fetal baboon lung: roles in lung growth and maturation. Am J Physiol 1999; 277: L1003-1017

12 Pan J, Copland I, Post $M$ et al. Mechanical stretch induced serotonin release from pulmonary neuroendocrine cells: implications for lung development. Am J Physiol Lung Cell Mol Physiol 2006; 290: L185193

13 Fu XW, Nurse CA, Wong V et al. Hypoxia-induced secretion of serotonin from intact pulmonary neuroepithelial bodies in neonatal rabbit. J Physiol 2002; 539: 503-510

14 Helset E, Kjaeve J, Bjertnaes $L$ et al. Acute alveolar hypoxia increases endothelin-1 release but decreases release of calcitonin gene-related peptide in isolated perfused rat lungs. Scand J Clin Lab Invest 1995; 55: $369-376$

15 Palmer JB, Cuss FM, Mulderry PK et al. Calcitonin gene-related peptide is localised to human airway nerves and potently constricts human airway smooth muscle. Br J Pharmacol 1987; 91: 95-101

16 Quaedvlieg PF, Visser O, Lamers CB et al. Epidemiology and survival in patients with carcinoid disease in The Netherlands. An epidemiological study with 2391 patients. Ann Oncol 2001; 12: 1295

17 Modlin IM, Lye KD, Kidd M. A 5-decade analysis of 13,715 carcinoid tumors. Cancer 2003; 97: 934

18 Hemminki $\mathrm{K}, \mathrm{Li} \mathrm{X}$. Incidence trends and risk factors of carcinoid tumors. Cancer 2001; 92: 2204

19 Hauso O, Gustafsson BI, Kidd M et al. Neuroendocrine tumor epidemiology: contrasting Norway and North America. Cancer 2008; 113 : 2655

20 Naalsund A, Rostad H, Strom EH et al. Carcinoid lung tumors incidence, treatment and outcomes: a population-based study. Eur J Cardiothorac Surg 2011; 39: 565-569

21 Fink G, Krelbaum T, Yellin A et al. Pulmonary carcinoid: presentation, diagnosis, and outcome in 142 cases in Israel and review of 640 cases from the literature. Chest 2001; 119: 1647 
22 Gatta G, Ciccolallo L, Kunkler I et al. Survival from rare cancer in adults: a population-based study. Lancet Oncol 2006; 7: 132

23 Skuladottir H, Hirsch FR, Hansen HH et al. Pulmonary neuroendocrine tumors: incidence and prognosis of histological subtypes. A population-based study in Denmark. Lung Cancer 2002; 37: 127-135

24 Yao JC, Hassan M, Phan A et al. One hundred years after "carcinoid": epidemiology of and prognostic factors for neuroendocrine tumors in 35,825 cases in the United States. J Clin Oncol 2008; 26: 3063

25 US National Cancer Institute. Surveillance Epidemiology and End Results (SEER) data base, 1973-2004. http://seer.cancer.gov/2007

26 Takei H, Asamura H, Maeshima A et al. Large cell neuroendocrine carcinoma of the lung: a clinicopathologic study of eighty-7 cases. J Thorac Cardiovasc Surg 2002; 124: 285-292

27 Veronesi G, Morandi U, Alloisio $M$ et al. Large cell neuroendocrine carcinoma of the lung: a retrospective analysis of 144 surgical cases. Lung Cancer 2006; 53: 111-115

28 Beasley MB, Thunnissen FBJM, Brambilla E et al. Pulmonary atypical carcinoid: predictors of survival in 106 cases. Hum Pathol 2000; 31: $1255-1265$

29 Erasmus JJ, McAdams HP, Patz EF Jr et al. Evaluation of primary pulmonary carcinoid tumors using FDG PET. AJR Am J Roentgenol 1998; 170: $1369-1373$

30 Kayser K, Kayser C, Rahn W et al. Carcinoid tumors of the lung: emorrand ligandohistochemistry, analysis of integrated optical density, syntactic structure analysis, clinical data, and prognosis of patients treated surgically. J Surg Oncol 1996; 63: 99-106

31 Oliveira AM, Tazelaar HD, Wentzlaff KA et al. Familial pulmonary carcinoid tumors. Cancer 2001; 91: 2104

32 Padberg $B$ et al. Multiple endocrine neoplasia type 1 (MEN1) revisited. Virchows Arch 1995; 426: 541 -548

33 Sachithanandan N, Harle RA, Burgess JR. Bronchopulmonary carcinoid in multiple endocrine neoplasia type 1. Cancer 2005; 103: 509-515

34 Walch AK, Zitzelsberger HF, Aubele MM et al. Typical and atypical carcinoid tumors of the lung are characterized by $11 \mathrm{q}$ deletions as detected by comparative genomic hybridization. Am J Pathol 1998; 153: $1089-1098$

35 Debelenko LV, Swalwell JI, Kelley MJ et al. MEN1 gene mutation analysis of high-grade neuroendocrine lung carcinoma. Genes Chromosomes Cancer 2000; 28: 58 - 65

36 Debelenko LV, Brambilla E, Agarwal SK et al. Identification of MEN1 gene mutations in sporadic carcinoid tumors of the lung. Hum Mol Genet 1997; 6: 2285-2290

37 Brandi ML, Gagel RF, Angeli A et al. Guidelines for diagnosis and therapy of MEN type 1 and type 2. J Clin Endocrinol Metab 2001; 86: $5658-5671$

38 Gustafsson BI, Kidd M, Chan A et al. Bronchopulmonary neuroendocrine tumors. Cancer 2008; 113: 5-21

39 Travis WD, Brambilla E, Muller-Hermlink HK et al. World Health Organization Classification of Tumors. Pathology and Genetics of Tumours of the Lung, Pleura, Thymus and Heart. Lyon, France: IARC Press; 2004: 196-198

40 Aubry MC, Thomas CFJr, Jett JR et al. Significance of multiple carcinoid tumors and tumorlets in surgical lung specimens: Analysis of 28 patients. Chest 2007; 131: 1635-1643

41 D'Agati VD, Perzin KH. Carcinoid tumorlets of the lung with metastasis to a peribronchial lymph node. Report of a case and review of the literature. Cancer 1985; 55: 2472-2476

42 Hausman DH, Weimann RB. Pulmonary tumorlet with hilar lymph node metastasis. Report of a case. Cancer 1967; 20: 1515-1519

43 Travis WD. Advances in neuroendocrine lung tumors. Annals of Oncology 2010; 21 (Suppl. 07): vii65 - vii71

44 Pelosi G, Rodriguez J, Viale G et al. Typical and atypical pulmonary carcinoid tumor overdiagnosed as small-cell carcinoma on biopsy specimens: a major pitfall in the management of lung cancer patients. Am J Surg Pathol 2005; 29: 179-187

45 Sturm N, Rossi G, Lantuejoul S et al. 34betaE12 expression along the whole spectrum of neuroendocrine proliferations of the lung, from neuroendocrine cell hyperplasia to small cell carcinoma. Histopathology 2003; 42: $156-166$

46 Folpe $A L$, Gown AM, Lamps $L W$ et al. Thyroid transcription factor-1: immunohistochemical evaluation in pulmonary neuroendocrine tumors. Mod Pathol 1999; 12: 5-8

47 Sturm N, Rossi G, Lantuejoul S et al. Expression of thyroid transcription factor- 1 in the spectrum of neuroendocrine cell lung proliferations with special interest in carcinoids. Hum Pathol 2002; 33: 175-182
48 Roggli VL, Vollmer RT, Greenberg SD et al. Lung cancer heterogeneity: a blinded and randomized study of 100 consecutive cases. Hum Pathol 1985; 16 : $569-579$

49 Travis WD, Gal AA, Colby TV et al. Reproducibility of neuroendocrine lung tumor classification. Hum Pathol 1998; 29: 272 -279

50 Kema IP, de Vries EG, Slooff MJ et al. Serotonin, catecholamines, histamine, and their metabolites in urine, platelets, and tumor tissue of patients with carcinoid tumors. Clin Chem 1994; 40: 86-95

51 Feldman JM. Serotonin metabolism in patients with carcinoid tumors: incidence of 5-hydroxytryptophan-secreting tumors. Gastroenterology 1978; 75: 1109-1114

52 Castiello RJ, Lynch PJ. Pellagra and the carcinoid syndrome. Arch Dermatol 1972; 105: 574-577

53 Fischer S, Kruger M, McRae K et al. Giant bronchial carcinoid tumors: a multidisciplinary approach. Ann Thorac Surg 2001; 71: 386

54 Karmy-Jones R, Vallieres E. Carcinoid crisis after biopsy of a bronchial carcinoid. Ann Thorac Surg 1993; 56: 1403

55 Anderson AS, Krauss D, Lang $R$. Cardiovascular complications of malignant carcinoid disease. Am Heart J 1997; 134: 693-702

56 Kvols $L K$. Therapeutic considerations emorrh malignant carcinoid syndrome. Acta Oncologica 1989; 28: 433-438

57 Vincent JM, Trainer PJ, Reznek RH et al. The radiological investigation of occult ectopic ACTH-dependent Cushing's syndrome. Clin Radiol 1993; 48: 11

58 Aniszewski JP, Young WF Jr, Thompson GB et al. Cushing syndrome due to ectopic adrenocortictropic hormone secretion. World J Surg 2001 255: $934-940$

59 Deb SJ, Nichols FC, Allen MS et al. Pulmonary carcinoid tumors with Cushing's syndrome: an aggressive variant or not? Ann Thorac Surg 2005; 79: 1132

60 Scanagatta P, Montresor E, Pergher $S$ et al. Cushing's syndrome induced by bronchopulmonary carcinoid tumours: a review of 98 cases and our experience of two cases. Chir Ital 2004; 56: 63

61 Shrager JB, Wright CD, Wain JC et al. Bronchopulmonary carcinoid tumors associated with Cushing's 12emorrha: amore aggressive variant of typical carcinoid. Jthorac Cardiovasc Surg 1997; 14: 367

62 Pass HI, Doppmann JL, Niemann L et al. Management 12emorr ectopic ACTH syndrome due to thoracic carcinoids. Ann Thorac Surg 1990; 50: 52

63 Faglia G, Arosio M, Bazzoni N. Ectopic acromegaly. Endocrinol Metab Clin North Am 1992; 21: 575-595

64 Scheithauer BW, Carpenter PC, Bloch B et al. Ectopic secretion of a growth hormone-releasing factor. Report of a case of acromegaly with bronchial carcinoid tumor. Am J Med 1984; 76: 605

65 Garcia-Luna PP, Leal-Cerro A, Montero C et al. A rare cause of acromegaly: ectopic production of growth hormone-releasing factor by a bronchial carcinoid tumor. Surg Neurol 1987; 27: 563

66 Athanassiadi K, Exarchos D, Tsagarakis $S$ et al. Acromegaly caused by ectopic growth hormone-releasing hormone secretion by a carcinoid bronchial tumor: a rare entity. J Thorac Cardiovasc Surg 2004; 128: 631

67 Bhansali A, Rana SS, Bhattacharya S et al. Acromegaly: a rare manifestation of bronchial carcinoid. Asian Cardiovasc Thorac Ann 2002; 10 : 273

68 Reuters VS, Dias EMR, Pupo MRSR et al. Acromegaly secondary to ectopic growth hormone-releasing hormone-secreting bronchial carcinoid cured after pneumectomy. Endocrinologist 2003; 13: 376 379

69 Bolanowski M, Schopol J, Marcianak $M$ et al. Acromegaly due to GHRH-secreting large bronchial carcinoid. Complete recovery following tumor surgery. Exp Clin Endocrinol Diabets 2002; 110: 188-192

70 Krassoswski J, Zgliczynski W, Jeske $W$ et al. Comment on long-acting lanreotide inducing clinical and biochemical remission of acromegaliy caused by disseminated GHRH secreting carcinoid. J Clin Endocrinol Metab 1999; 84: 1761 - 1762

71 Gustafsson BI, Tommeras K, Nordrum I et al. Long-term serotonin administration induces heart valve disease in rats. Circulation 2005; 111: $1517-1522$

72 Musunuru S, Carpenter JE, Sippel RS et al. A mouse model of carcinoid syndrome and heart disease. J Surg Res 2005; 126: 102 - 105

73 Greminger P, Hess OM, Muller AE et al. Bronchial neuroendocrine (carcinoid) tumor causing unilateral left-sided carcinoid heart disease. Klin Wochenschr 1991; 69: 128-133 
74 Westberg G, Wangberg B, Ahlman $H$ et al. Prediction of prognosis by Echocardiography in patients with midgut carcinoid syndrome. $\mathrm{Br} \mathrm{J}$ Surg 2001; 88: 865-872

75 Oberg K. Neuroendocrine gastrointestinal tumors-a condensed overview of diagnosis and treatment. Ann Oncol 1999; 10 (Suppl. 02): S3-S8

76 Gustafsson BI, Hauso O, Drozdov I et al. Carcinoid heart disease. Int J Cardiol 2008 Oct 13; 192 (Suppl. 03): 318-324

77 Pieroni $M$ et al. Myocardial production of chromogranin A in human heart: a new regulatory peptide of cardiac function. Eur Heart J 2007; 28: $1117-1127$

78 Nobels FR, Kwekkeboom DJ, Coopmans W et al. Chromogranin A as serum marker for neuroendocrine neoplasia: comparison with neuronspecific enolase and the alpha-subunit of glycoprotein hormones. J Clin Endocrinol Metab 1997; 82: 2622 - 2628

79 Sciarra A, Monti S, Gentile Vet al. Chromogranin A expression in familial versus sporadic prostate cancer. Urology 2005; 66: 1010-1014

80 Bieglmayer $C$ et al. Chromogranin A: Ein universeller Marker neuroendokriner Tumoren. Austrian Journal of Clinical Endocinology and Metabolism 2010; 3: 8-14

81 Kema IP, Schellings AM, Meiborg G et al. Influence of aserotonin- and dopamine-rich diet on platelet serotonin content and urinary excretion of biogenic amines and their metabolites. Clin Chem 1992; 38: $1730-1736$

82 Kema IP, de Vries EG, Schellings AM et al. Improved Diagnosis of Carcinoid Tumors by Measurement of Platelet Serotonin. Clin Chem 1992; 38: $534-540$

83 Bajetta E, Ferrari L, Martinetti A et al. Chromogranin A, neuron specific enolase, carcinoembryonic antigen, and hydroxyindole acetic acid evaluation in patients with neuroendocrine tumors. Cancer 1999; 86: $858-865$

84 Cunningham RT, Johnston CF, Irvine GB et al. Serum neuron-specific enolase levels in patients with neuroendocrine and carcinoids tumours. Clin Chem Acta 1992; 212: 123 - 131

85 Rosado de Christenson ML, Abbott GF, Kirejczyk WM et al. Thoracic carcinoids: radiologicpathologic correlation. RadioGraphics 1999; 19: $707-736$

86 Gould PM, Bonner JA, Sawyer TE et al. Bronchial carcinoid tumors: importance of prognostic factors that influence patterns of recurrence and overall survival. Radiology 1998; 208: $181-185$

87 Magid D, Siegelman SS, Eggleston JC et al. Pulmonary carcinoid tumors: CT assessment. J Comput Assist Tomogr 1989; 13: 244

88 Zwiebel BR, Austin JH, Grimes MM. Bronchial carcinoid tumors: assessment with CT of location and intratumoral calcification in 31 patients. Radiology 1991; 179: 483-486

89 Takamochi $K$, Yokose T, Yoshida J et al. Calcification in large cell neuroendocrine carcinoma of the lung. Jpn J Clin Oncol 2003; 33: 10-13

90 Chong S, Lee KS, Chung MJ et al. Neuroendocrine tumors of the lung: Clinical, Pathologic, and Imaging Findings. RadioGraphics 2006; 26: $41-45$

91 Sutedja G, Golding RP, Postmus PE. High resolution computed tomography in patients referred for intraluminal bronchoscopic therapy with curative intent. Eur Respir J 1996; 9: 1020-1023

92 Douek PC, Simoni L, Revel D et al. Diagnosis of bronchila carcinoid tumor by ultrafast contrast-enhanced MR imaging. AJR Am J Roentgenol 1994; 163: 563

93 Aron M, Kapila K, Verma K. Carcinoid tumors 15emorr lung: a diagnostik challenge in bronchial washings. Diagn Cytopath 2004; 30: 62

94 Nguyen GK. Cytopathology of pulmonary carcinoid tumors in sputum and bronchial brushings. Acta Cytol 1995; 39: 1152

95 Todd TR, Cooper JD, Weissberg D et al. Bronchial carcinoid tumors: twenty years' experience. Thorac Cardiovasc Surg 1980; 79: 532 - 535

96 Fink $G$, Krelbaum T, Yellin A et al. Pulmonary carcinoid: presentation, diagnosis, and outcome in 142 cases in Israel and review of 640 cases from the literature. Chest 2001; 119: 1647-1651

97 Kurimoto N, Murayama M, Yoshioka $S$ et al. Assessment of usefulness of endobronchial ultrasonography in determination of depth of tracheobronchial tumor invasion. Chest 1999; 115: 1500-1506

98 Becker $\mathrm{H}$. Endobronchialer Ultraschall. Eine neue Perspektive in der Bronchologie. Ultraschal in Med 1996; 17: 106-112

99 Van Boxen TJ, Venmans BJ, van Mourik JC et al. Bronchoscopic treatment of intraluminal typical carcinoid: a pilot study. J Thorac Cardiovasc Surg 1998; 116: $402-406$

100 Ryan PJ, Fogelmann I. The role of nuclear medicine in orthopaedics. Nuclear Medicine Communications 1994; 15: 341-60
101 Focacci C, Lattanzi R, Iadeluca ML et al. Nuclear medicine in primary bone tumors. European Journal of Radiology 1998; 27: 123-31

102 Krenning EP, Bakker WH, Breeman WA et al. Localization of endocrinerelated tumours with a radioiodinated analogue of somatostatin. Lancet 1989; 1: $242-244$

103 Reubi JC, Schar JC, Waser B et al. Affinity profiles for human somatostatin receptor subtypes SST1. SST5 of somatostatin tracers selected for scintigraphic and radiotherapeutic use. Eur J Nucl Med 2000; 27 : $273-282$

104 Hoefnagel CA, den Hartog Jager FC, Taal BG et al. The role of I-131MIBG in the diagnosis and therapy of carcinoids. Eur J Nucl Med 1987; 13: $187-191$

105 Eriksson B, Bergstrom M, Sundin A et al. The role of PET in localization of neuroendocrine and adrenocortical tumors. Ann N Y Acad Sci 2002; 970: 159-169

106 Baum RP, Hofmann M. Nuklearmedizinische Diagnostik neuroendokriner Tumoren. Onkologe 2004; 10: 598-610

107 Kowalski J, Henze M, Schuhmacher J et al. Evaluation of positron emission tomography imaging using Ga-68 DOTA-D Phe(1)-Tyr(3)-Octreotide in comparison to In-111-DTPAOC SPECT. First results in patients with neuroendocrine tumors. Mol Imaging Biol 2003; 5: 42 48

108 Gabriel M, Decristoforo C, Kendler D et al. 68Ga-DOTATyr3-octreotide PET in neuroendocrine tumors: comparison with somatostatin receptor scintigraphy and CT. J Nucl Med 2007; 48: 508-518

109 Orlefors H, Sundin A, Garske $U$ et al. Whole-body C-5-hydroxytryptophan positron emission tomography as a universal imaging technique for neuroendocrine tumors: comparison with somatostatin receptor scintigraphy and computed tomography. J Clin Endocrinol Metab 2005; 90: $3392-3400$

110 Koopmans KP, Neels OC, Kema IP et al. Improved staging of patients with carcinoid and islet cell tumors with 18F-dihydroxy-phenyl-alanine and 11C-5-hydroxy-tryptophan positron emission tomography. J Clin Oncol 2008; 26: 1489-95

111 Kayani I. A Comparison of 68Ga-DOTATATE and 18F-FDG PET/CT in Pulmonary Neuroendocrine Tumors. J Nucl Med December 2009; 50: $1927-1932$

112 Filosso PL, Rena O, Donati G et al. Bronchial carcinoid tumors: surgical management and long-term outcome. J Thorac Cardiovasc Surg 2002; 123: $303-309$

113 Cooper WA, Thourani VH, Gal AA et al. The surgical spectrum of pulmonary neuroendocrine neoplasms. Chest 2001; 119: 14-18

114 Martini N, Zaman MB, Bains MS et al. Treatment and prognosis in bronchial carcinoids involving regional lymph nodes. J Thorac Cardiovasc Surg 1994; 107: 1 -6

115 Davila DG, Dunn WF, Tazelaar HD et al. Bronchial carcinoid tumors, Mayo Clin Proc 1993; 68: 795-803

116 McCaughan BC, Martini N, Bains MS. Bronchial carcinoids. Review of 124 cases. J Thorac Cardiovasc Surg 1985; 89: 8-17

117 Iyoda A, Hiroshima K, Nakatani Y et al. Pulmonary large cell neuroendocrine carcinoma: its place in the spectrum of pulmonary carcinoma. Ann Thorac Surg 2007; 84: 702 - 707

118 Cardillo G, Sera F, Di Martino M et al. Bronchial carcinoid tumors: nodal status and long - term survival after resection. Ann Thorac Surg 2004; 77: $1781-1785$

119 Garcia-Yuste M, Matilla J, Alvarez-Gago T et al. Prognostic factors in neuroendocrine lung tumors: a Spanish multicenter study. Ann Thorac Surg 2000; 70: 258-263

120 Schreurs A, Westermann C, van den Bosch J et al. A twenty-five-year follow-up of ninety-three resected typical carcinoid tumors of the lung. J Thorac Cardiovasc Surg 1992; 104: 1470-1475

121 Marty-Ane C, Costes V, Pujol J et al. Carcinoid tumors of the lung: do atypical features require aggressive management? Ann Thorac Surg 1995; 59: $78-83$

122 Bertoletti L, Elleuch R, Kaczmarek D et al. Bronchoscopic cryotherapy treatment of isolated endoluminal typical carcinoid tumor. Chest 2006; 130: $1405-1411$

123 Luckraz H, Amer K, Thomas L et al. J Thorac Cardiovasc Surg 2006; 132: $113-115$

124 Cavaliere S, Focoli P, Toninelli C. Curative bronchoscopic laser therapy for surgically resectable tracheobronchial tumors. J Bronchol 2002; 9: 90-95

125 Mackley HB, Videtic GM. Primary carcinoid tumors of the lung: a role for radiotherapy. Oncology (Williston Park) 2006; 20: 1537-1543 
126 Ameer F, Zubairi AB, Fawad MU et al. Bronchial carcinoid presenting with abdominal pain. J Coll Physicians Surg Pak 2005; 15: 498 - 499

127 Chakravarthy A, Abrams RA. Radiation therapy in the management of patients with malignant carcinoid tumors. Cancer 1995; 75: 1386 1390

128 Yamazaki S, Sekine I, Matsuno Y et al. Clinical responses of large cell neuroendocrine carcinoma of the lung to cisplatin-based chemotherapy. Lung Cancer 2005; 49: 217-223

129 Rossi G et al. Role of Chemotherapy and the Receptor Tyrosine Kinases KIT, PDGFR-Alpha PDGFRß, and Met in Large-Cell Neuroendocrine Carcinoma of the Lung. J Clin Oncol 2005 Dec 1; 23 (Suppl. 34): $8774-8785$

130 Fujiwara Yet al. Effect of platinum combined with irinotecan or paclitaxel against large cell neuroendocrine carcinoma of the lung. Jpn J Clin Oncol 2007; 37: 482-486

131 Granberg D, Eriksson B, Wilander $E$ et al. Experience in treatment of metastatic pulmonary carcinoid tumors. Annals of Oncology 2001; 12: $1383-1391$

132 Ekeblad $S$ et al. Temozolomide as monotherapy is effective in treatment of advanced malignant neuroendocrine tumors. Clin Cancer Res 2007; 13: 2986-2991

133 Niho $S$ et al. Combination Chemotherapy with Irinotecan and Cisplatin for Large-Cell Neuroendocrine Carcinoma of the Lung: A Multicenter Phase II Study. J Thorac Oncol 2013; 8: 980-984

134 Pyronnet $S$, Bousquet C, Najib S et al. Antitumor effects of somatostatin. Mol Cell Endocrinol 2008; 286: 230-237

135 Woltering EA, Watson JC, Alperin-Lea RC et al. Somatostatin analogs: angiogenesis inhibitors with novel mechanisms of action. Invest New Drugs 1997; 15: 77-86

136 Bousquet C, Puente E, Buscail L et al. Antiproliferative effect of somatostatin and analogs. Chemotherapy 2001; 47: $30-39$

137 Rinke A, Müller $\mathrm{HH}$ et al. Placebo controlled, double blind, prospective, randomized study on the effect of octreotide LAR in the control of tumor growth in Patients with metastasic neuroendocrine midgut tumors: a report from the PROMID Study Group. J Clin Oncol 2009; 27: $4656-4663$

138 Tiensuu Janson EM, Ahlström H, Andersson T et al. Octreotide and interferon alfa: a new combination for the treatment of malignant carcinoid tumours. Eur J Cancer 1992; 28: 1647-1650

139 Faiss S, Pape UF, Bohmig M et al. Prospective, randomized, multicenter trial on the antiproliferative effect of lanreotide, interferon alfa, and their combination for therapy of metastatic neuroendocrine gastroenteropancreatic tumorsVthe International Lanreotide and Interferon Alfa Study Group. J Clin Oncol 2003; 21: 2689-2696

140 Arnold R. Combination therapy with octreotide and alpha-interferon: effect on tumor growth in metastatic endocrine gastroenteropancreatic tumors. Am J Gastroenterol 1999 May; 94(Suppl. 05): 1381 1387
141 Yao JC, Phan A, Hoff PM et al. Targeting vascular endothelial growth factor in advanced carcinoid tumor: a random assignment phase II study of depot octreotide with bevacizumab and pegylated interferon alpha-2b. J Clin Oncol 2008; 26: 1316-1323

142 Pavel ME, Hainsworth JD, Baudin E et al. for the RADIANT-2 Study Group. 25. 11. 2011: DOI: DOI 10.1016/S0140-6736(11)61742Xwww.thelancet.com

143 Fazio N, Granberg $D$ et al. Everolimus Plus Octreotide Long-Acting Repeatable in Patients With Advanced Lung Neuroendocrine Tumors Analysis of the Phase 3, Randomized, Placebo-Controlled RADIANT-2 Study. Chest 2013; 143: 955-962 doi: DOI 10.1378/chest.12-1108

144 Kulke MH, Lenz HJ, Meropol NJ et al. Activity of sunitinib in patients with advanced neuroendocrine tumors. J Clin Oncol 2008; 26: $3403-3410$

145 Raymond E, Dahan L et al. Sunitinib Malate for the Treatment of Pancreatic Neuroendocrine Tumors. N Engl J Med 2011; 364: 1082

146 Kwekkeboom DJ et al. Treatment with the radiolabeled somatostatin analog [177 Lu-DOTA 0,Tyr3] octreotate: toxicity, efficacy, and survival. J Clin Oncol 2008; 26: 2124-30 doi: DOI 10.1200/ JCO.2007.15.2553

147 Baum RP. Peptidrezeptorvermittelte Radiotherapie (PRRT) neuroendokriner Tumoren Klinische Indikationen und Erfahrung mit 90Yttrium-markierten Somatostatinanaloga. Onkologe 2004; 10: $1098-1110$

148 Van Essen M, Krenning EP, Bakker WH et al. Peptide receptor radionuclide therapy with $177 \mathrm{Lu}$ - octreotate in patients with foregut carcinoid tumours of bronchial, gastric and thymic origin. Eur J Nucl Med Mol Imaging 2007; 34: 1219-1227

149 Van Essen M, Krenning EP, Kooij PP et al. Effects of therapy with [177Lu-DOTA0, Tyr3] octreotate in patients with paraganglioma, meningioma, small cell lung carcinoma, and melanoma. J Nucl Med 2006; 47: 1599-1606

150 Baum RP, Kulkarni HR. THERANOSTICS: From Molecular Imaging Using Ga-68 Labelled Tracers and PET/CT to Personalized Radionuclide Therapy - The Bad Berka Experience. Theranostics 2012; 2: 437 447 [Published online 2012 May 7] DOI 10.7150/thno.3645

151 Thomas CF Jr, Tazelaar HD, Jett JR. Typical and atypical pulmonary carcinoids: outcome in patients presenting with regional lymph node involvement. Chest 2001; 119: 1143 -1150

152 Travis WD, Rush W, Flieder DB et al. Survival analysis of 200 pulmonary neuroendocrine tumors with clarification of criteria for atypical carcinoid and its separation from typical carcinoid. Am J Surg Pathol 1998; 22: $934-944$

153 Merrill RM, Henson DE, Barnes M. Conditional survival among patients with carcinoma of the lung. Chest 1999; 116: 697-703

154 Elliott JA, Osterlind K, Hirsch FR et al. Metastatic patterns in small cell lung cancer: correlation of autopsy findings with clinical parameters in 537 patients. J Clin Oncol 1987; 5: 246-254 